\title{
Multi-criteria comparative analysis of the pressure drop on coal gangue fly-ash slurry at different parts along an L-shaped pipeline
}

\section{Defeng Wang}

TU Bergakademie Freiberg: Technische Universitat Bergakademie Freiberg

\section{Dengwu Jiao}

Ghent University Faculty of Engineering and Architecture: Universiteit Gent Faculteit Ingenieurswetenschappen en Architectuur

Zhanbo Cheng

University of Warwick

\section{Qingwen Shi}

West Virginia State University

Helmut Mischo ( $\square$ Helmut.Mischo@mabb.tu-freiberg.de )

Technical University of Bergakademie Freiberg

\section{S.I. : Integrated Development of Transportation and Energy}

Keywords: coal gangue slurry, pressure drop, numerical simulation, response surface analysis

Posted Date: February 8th, 2022

DOI: https://doi.org/10.21203/rs.3.rs-1295051/v1

License: (c) (i) This work is licensed under a Creative Commons Attribution 4.0 International License. Read Full License 


\title{
Multi-criteria comparative analysis of the pressure drop on coal gangue fly- ash slurry at different parts along an L-shaped pipeline
}

\author{
Defeng Wang ${ }^{\mathrm{a}}$, Dengwu Jiao ${ }^{\mathrm{b}}$, Zhanbo Cheng ${ }^{\mathrm{c}}$, Qingwen Shi ${ }^{\mathrm{d}^{*}}$, Helmut Mischo ${ }^{\mathrm{a}^{*}}$ \\ ${ }^{a}$ Institute of Mining and Special Civil Engineering, Technical University of Bergakademie \\ Freiberg, Freiberg 09599, Dresden, Germany
}

${ }^{b}$ Faculty of engineering and architecture department of structural engineering and building

materials, Ghent university, 9052 Zwijnaarde, Belgium

${ }^{c}$ School of Engineering, University of Warwick, Coventry CV47AL, UK

${ }^{d}$ West Virginia University, Morgantown 26505, USA

${ }^{*}$ Corresponding Author 1

Email: Helmut.Mischo@mabb.tu-freiberg.de

Department for Underground Mining Methods, Institute of Mining, Technical University Bergakademie Freiberg, Fuchsmühlenweg 9, 09599, Freiberg, DE- Germany

*Corresponding Author 2

Email: qs0003@mix.wvu.edu

Department of Engineering, West Virginia University, Morgantown 26505,USA

\begin{abstract}
Disposing coal gangue and fly-ash on the surface is a risky method which has tremendous potential catastrophic consequences for the environment, whereas backfill mining is a promising practice turing those hazardous wastes into useful backfill materials. Unfortunately, how to deliver the slurry into avoid efficiently remains underresearched, therefore, to address this gap, in the present paper, in addition to a laboratory rheological test, computational fluid dynamics software Fluent was also employed to simulate the different effects that individual variables have on the pressure evolution at a specific section of the pipeline. Furthermore, the response surface method was implemented to examine how the multiple factors synergistically affect the pressure drop and their corresponding influencing weights. This paper shows that slurry concentration, speed, and pipe diameter all significantly affect the pressure drop of slurry and that conveying speed is the dominant factor in the bend section. In contrast, pipe diameter becomes the dominant factor in the horizontal and vertical pipe sections.
\end{abstract}

Keywords: coal gangue slurry; pressure drop; numerical simulation; response surface analysis;

\section{Statements and Declarations}

The authors declare that there are no conflicts of interest in connection with the work submitted. 


\title{
Multi-criteria comparative analysis of the pressure drop on coal gangue fly- ash slurry at different parts along an L-shaped pipeline
}

\begin{abstract}
Disposing coal gangue and fly-ash on the surface is a risky method which has tremendous potential catastrophic consequences for the environment, whereas backfill mining is a promising practice turing those hazardous wastes into useful backfill materials. Unfortunately, how to deliver the slurry into avoid efficiently remains underresearched, therefore, to address this gap, in the present paper, in addition to a laboratory rheological test, computational fluid dynamics software Fluent was also employed to simulate the different effects that individual variables have on the pressure evolution at a specific section of the pipeline. Furthermore, the response surface method was implemented to examine how the multiple factors synergistically affect the pressure drop and their corresponding influencing weights. This paper shows that slurry concentration, speed, and pipe diameter all significantly affect the pressure drop of slurry and that conveying speed is the dominant factor in the bend section. In contrast, pipe diameter becomes the dominant factor in the horizontal and vertical pipe sections.
\end{abstract}

Keywords: coal gangue slurry; pressure drop; numerical simulation; response surface analysis;

\section{Introduction}

Coal gangue as a kind of solid wastes from coal extraction and coal processing operation is usually abandoned on the surface due to its low abundance of usefull resources (Gao et al., 2021; Xie et al., 2021). However, exposing the toxic coal gangue in the air can arouse severe pollution, for instance, it will not only emit a large amount of greenhouse gas, but also pollute the groundwater when the toxic substances seep into the ground with rain. Fly ash is a byproduct produced during coal combustion in electric utility and captured from the flue gases using electrostatic precipitators. Every year tremendous valuable land was occupied by disposing of fly- ash worldwide.

In mine sector the backfill mining approach is becaming increasingly favoured, given 
its many advantages in reducing pollution. This mining method is a perfect way to diacard the aforementioned solid wastes and to reduce the risk of local and regional ground failure from collapse or subsidence (Wang et al., 2022; Shi et al., 2021). Therefore , using coal gangue as coarse aggregate and using fly ash replace some percent of ordinary Portland cement in making cemented coal gangue paste slurry are of considerable interest (Senapati and Mishra, 2012).

Conveying non-Newtonian slurry through the pipeline to the desired places is commonly encountered in many industrial sectors, for instance, food-producing, civil engineering, mining, et al. (Kaczmarczyk et al., 2021; Liu et al., 2021). Therefore, investigations about pipeline transportation-related problems were conducted intensively by scholars worldwide (Mohsen et al., 2019; Mohsen et al., 2020; Crawford et al., 2007).

The rheological characteristics of non-Newtonian fluid are fundamentally different from Newtonian fluid and relatively more complex (Picchi et al., 2018; Chhabra, 2010; Sercan and Oney,2020; Picchi et al., 2017). The pressure evolution of the non-Newtonian flow in the pipeline is affected by various factors. For instance, Qi et al. built a pilot transporting pipeline system with complex circuit shapes. The approach presented the backfill pressure drop due to the effects of solid content, cement-tailing ratio, inlet pressure, and circuit shape on the cemented paste. In addition, the researchers also analyzed the relative importance of influencing variables on the pressure drop (Qi et al., 2018). As reported in a research article, flow velocity, pipe shape, slurry concentration et cl. significantly impact pressure drop (Haixin 2018). Other than that, pressure drop in a specific pipe flow is also considerably affected by the cemented slurry's physical and chemical properties, such as the pipe diameter and the pipeline reticulation geometry (Yang et al., 2020). Beyond that, Easa and Barigon's research have validated the notable effect that particle size distribution has on flow regime (Eesa and Barigou, 2009). Jiang and his colleagues also carried out a series of 
similar investigations. Their study results corroborated that the particle size and shape can impact the rheological behavior of the slurry (Jiang et al., 2019). In a case study done by Senapati and Mishra, they suggest adjusting the diameter and slurry concentration to achieve their goal of changing the excess pressure head while transporting backfill materials to underground voids through vertically downward pipeline (Senapati and Mishra, 2012). Other than that, some researchers consider chemical reactions when calculating pressure drops in the pipeline; they created a coupled reaction model and implemented it in computational fluid dynamics software. The results proved the significance of hydration reaction on the paste flow character (Lang et al., 2019).

Although, as mentioned in the previous introduction of this paper, many scholars have conducted substantial research on the flow of non-Newtonian fluids in pipes under the influence of either single or multiple factors, they considered the pipeline as a whole. As a result, they ignored the flow patterns in different pipe sections. The negligence will lead to a vast disparity between the calculated and actual values of pipe pressure drop. Therefore, it is a potential danger to the safe operation of the material transmission or a waste of the pressure pump efficiency. As Wu stated in one of his works, accurately calculating the pressure drop along the pipeline is significant since it will cause a tremendous waste of energy when the pumping capacity of the pump installed exceeds the requirement for transporting slurry. In contrast, pipe blockage will occur when the pump capacity is not enough (Wu et al., 2015).

To investigate the pressure loss of slurry flow for backfilling through a pipeline, conducting experiments in the lab as a traditional way was usually adopted by many researchers worldwide (Bharathan et al., 2019; Chandel et al., 2009; Chen et al., 2015). Although laboratory experiments can restore many application scenarios to obtain credible data, the high cost of equipment and a significant amount of time spent in the experimental process seriously hinder researchers' enthusiasm. Benefiting from the improvement of computer computing power and the advancement of simulation software, more and more 
researchers have confirmed that fluid computing software to simulate the flow of highly concentrated slurries in pipes is an effective alternative to traditional lab experiments (Chen et al., 2017; Wu et al., 2018; Lahiri and Ghanta, 2010; Swamy et al., 2015; Kiran et al., 2019). Numerical simulations significantly reduce the cost of experimental materials and equipment, shorten the preparation time, and maximize the reproduction of field conditions that cannot be achieved in the laboratory (Cayeux and Leulseged, 2020; Gao et al., 2020).

Cemented coal gangue backfill method is a newly emerging backfill technique. This excavating method has many advantages compared with the collapse method as it can provide operators a safe working space, avoid surface subsidence, and dispose of solid wastes underground (Chen et al., 2020; Liang and Fall, 2016). The high-density slurry's flow features are consistent with non-Newtonian fluids, specifically Herschel-Bulkley fluid (Gharib et al., 2016; Mehta et al., 2021). Several reports have proved that the Herschel-Bulkley model is more efficient and accurate for predicting the rheological characteristics of non-Newtonian flows (Gharib et al., 2016; Bharathan et al., 2019; Huang et al., 2019; Taibi and Messelmi, 2018). Therefore, to find out how the various factors affect pressure profile at a different section of the pipeline, in the present study, several rheological tests of the coal-gangue-flyash slurry were firstly carried out to collect all the required parameters for the subsequent simulation. Then the Herchel-Bulkley, as mentioned above, the model was then deployed to simulate the three main influencing factors (flow velocity, pipe diameter, slurry concentration) effect on the pressure drop. After that, single-factor analysis and multi-factor response surface analysis for pressure drop were presented.

\section{Lab test}

\subsection{Materials}

The coal gangue used in this study was collected from a coal mine crushing plant located in Jining, Shandong Province, China. According to some researches, a particular 
portion of fine particles in the mixture can contribute to a steady and smooth convey for the slurries in the backfill pipeline. Therefore, two stages of coal gangue crushing were conducted in advance to meet the transporting requirements. The particle size distribution of coal gangue after crushing treatment was presented in Figure 1, and it can be seen that more than $70 \%$ of the coal gangue particles are below $5 \mathrm{~mm}$.

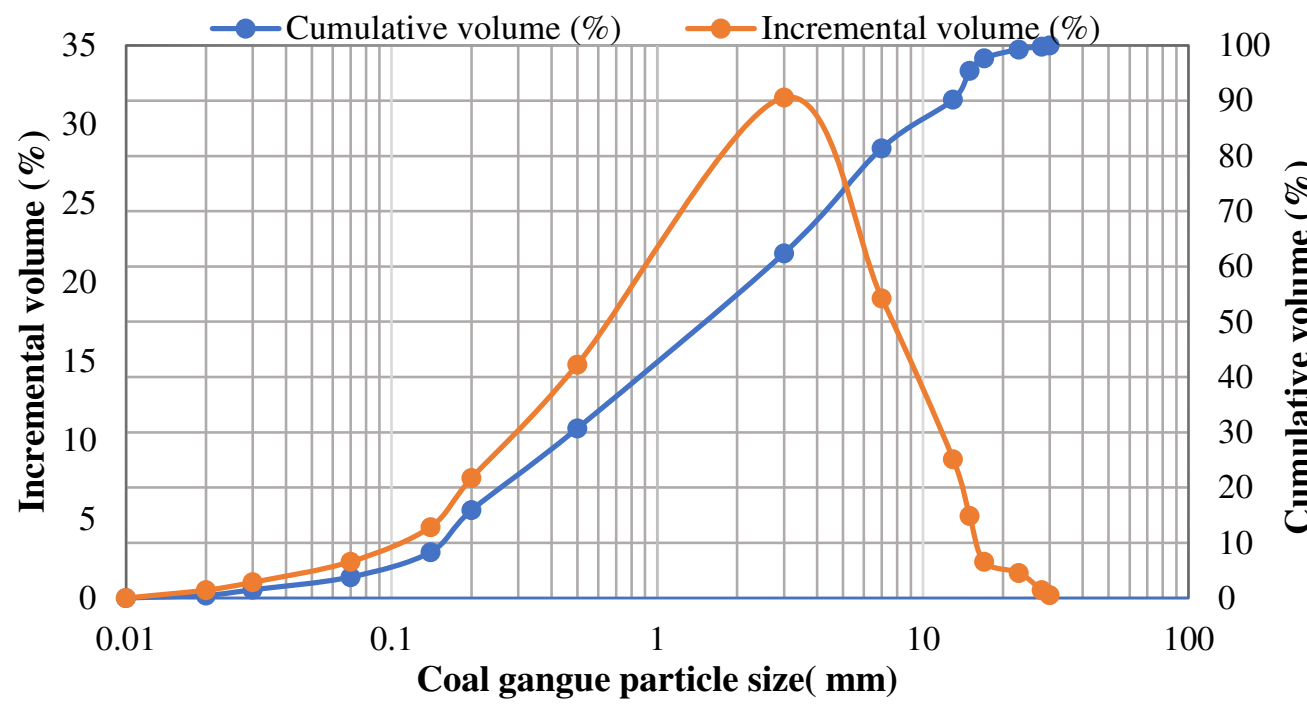

Figure 1. Coal gangue particle size distribution

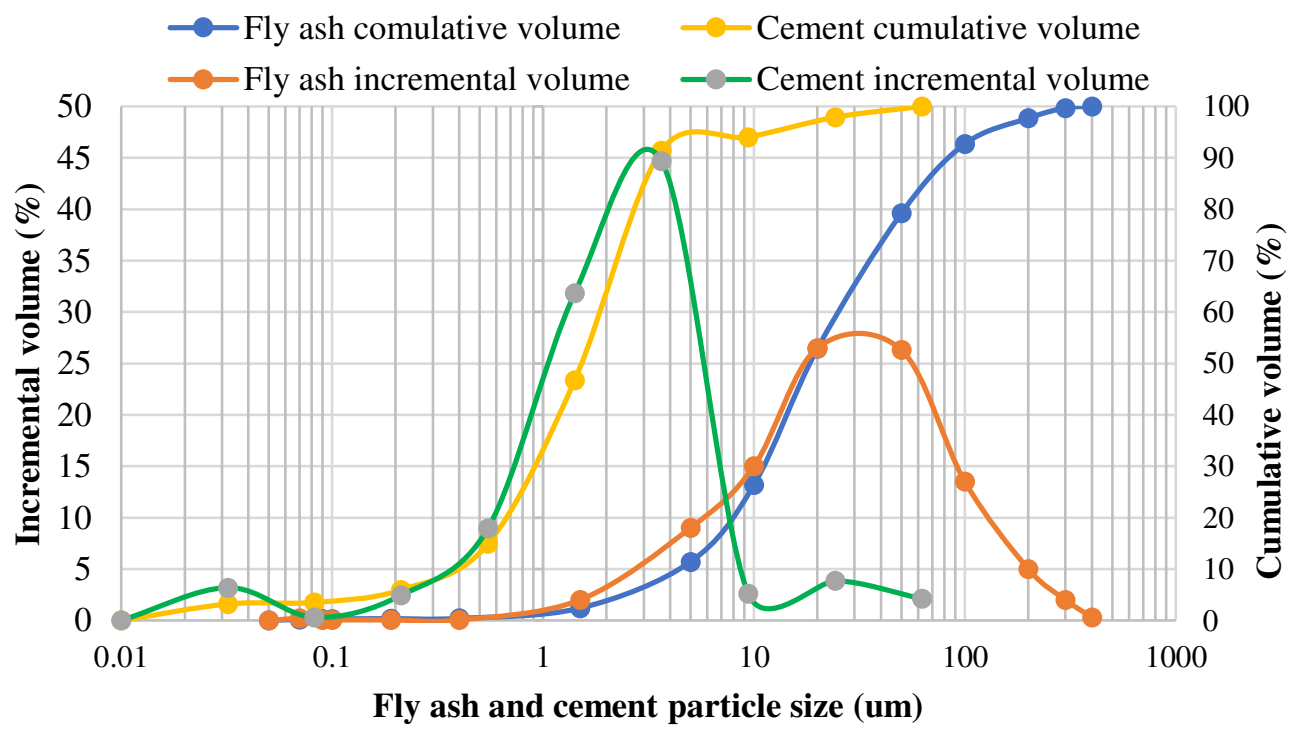

Figure 2. Fly ash and cement particle size distribution

The fly ash applied in the present study was obtained from a coal-fired power plant in Jining city, china, and the particle size distribution is plotted in Figure 2. The chemical composition of the coal gangue and fly ash was analyzed by X-ray diffraction and was 
summarized in Table1. The high content of $\mathrm{SiO} 2$ in the coal gangue indicates that the backfill mass supporting the surrounding rock and layer can meet the requirements. At the same time, the $\mathrm{CaO}$ content in fly ash categorizes it as a type $\mathrm{C}$ fly ash.

Table 1. Composition of coal gangue and fly ash

\begin{tabular}{lllllllllll}
\hline Classification & Composition & $\mathrm{Loss}$ & $\mathrm{SiO}_{2}$ & $\mathrm{Fe}_{2} \mathrm{O}_{3}$ & $\mathrm{Al}_{2} \mathrm{O}_{3}$ & $\mathrm{CaO}$ & $\mathrm{MgO}$ & $\mathrm{TiO}_{2}$ & $\mathrm{Na}_{2} \mathrm{O}$ & $\mathrm{K}_{2} \mathrm{O}$ \\
\hline Gangue & Percentage/\% & 17.8 & 51.92 & 3.87 & 19.03 & 1.0 & 1.18 & 0.75 & 0.54 & 1.47 \\
\hline Cement & Percentage/\% & 1.5 & 21.25 & 1.85 & 4.12 & 65.13 & 1.58 & 0.11 & 0.16 & 0.70 \\
\hline Fly ash & Percentage/\% & 10.33 & 43.84 & 27.40 & 4.01 & 12.13 & 1.09 & - & - & - \\
\hline
\end{tabular}

In the present study, fly ash and ordinary Portland cement are mixed as the binding agent in producing the backfill slurry, and the mixing ratio of FA and OPC by weight is 2 to 8. The crushed coal gangue particles are used as aggregates, and three levels of solid concentration slurry $(76 \%, 77 \%$, and $78 \%$, respectively) were prepared according to the research protocols. The mixing water is municipal tap water.

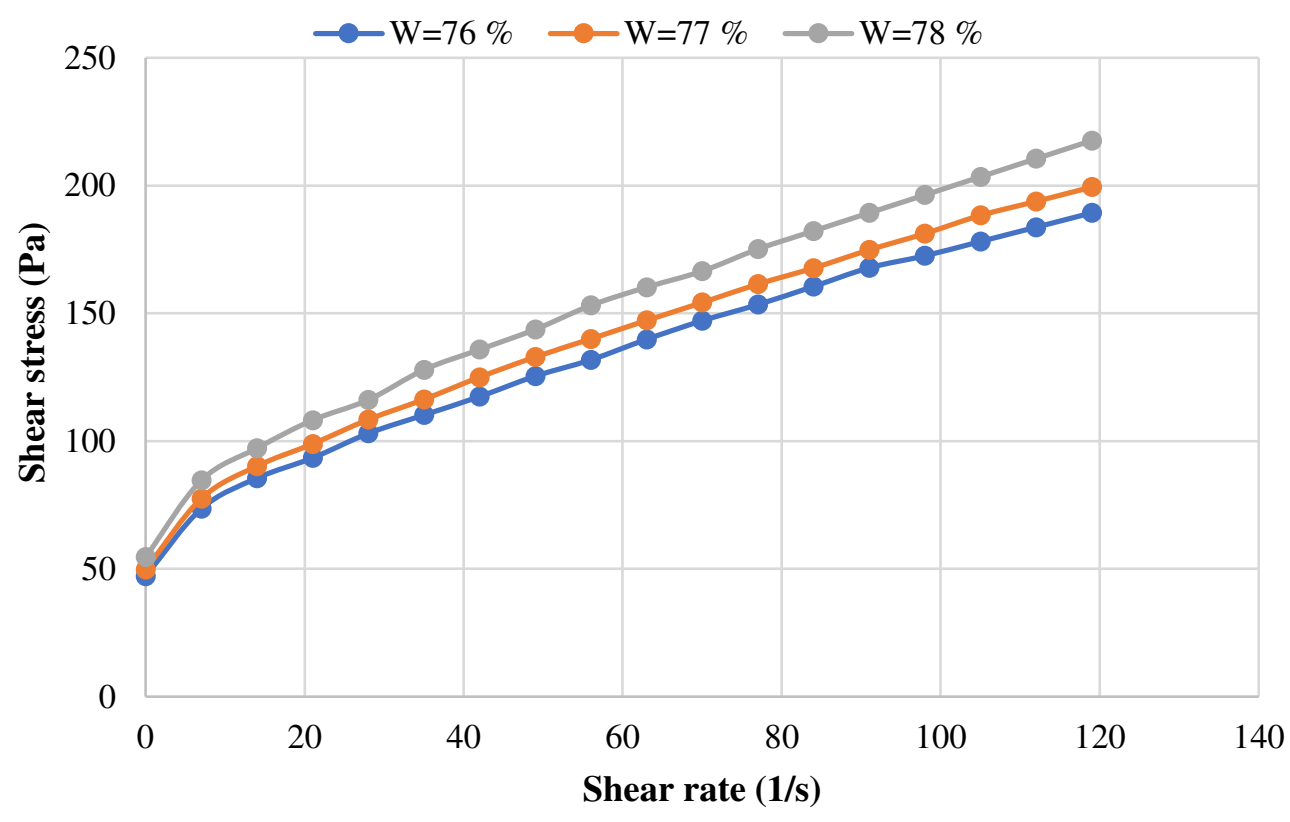

Figure 3. Backfill slurry rheological property

\subsection{Rheological test}

A series of rheological tests were carried out in the lab to acquire the essential 
parameters for the subsequent simulation experiments. And the sheer rate-shear stress relationship of the three slurries mentioned above with various solid concentrations is depicted in Figure 3. Significantly, the relationship is not linear, unlike the Newtonian flow, and the yield stress is needed to make the slurry flow. Consequently, based on the rheological experiments and previous scholar' reports Herschel-Bulkley model was adopted in this paper.

\section{Model building}

In this paper, a three-dimensional model which consists of three components (vertical section, bend section, horizontal section) was developed with the aid of software named Model-designer (see Figure 4). The length of both the vertical and horizontal sections is set as 10 meters while the radius of bend is 0.5 meters. This simulation model was built on the cartesian coordinate system, and 6 in total observation planes at $y=0.5 \mathrm{~m}, \mathrm{y}=4 \mathrm{~m}, \mathrm{y}=5 \mathrm{~m}$, $\mathrm{x}=0.5 \mathrm{~m}, \mathrm{x}=7 \mathrm{~m}$, and $\mathrm{x}=8 \mathrm{~m}$ was set up, respectively. In the subsequent data analysis, the pressure difference between the observation plane $\mathrm{y}=4 \mathrm{~m}$ and $\mathrm{y}=5 \mathrm{~m}$ represents the mean pressure loss of the slurry at the vertical pipe section. Similarly, the pressure gap between the observation surface $y=0.5 \mathrm{~m}$ and $\mathrm{x}=0.5 \mathrm{~m}$ represents the pressure drop at the bend. Finally, the pressure disparity between the observation plane $\mathrm{x}=7 \mathrm{~m}$ and $\mathrm{x}=8$ indicates the average pressure drop at the horizontal stage.

There are two general methods in studying the flow characteristics of fluids, one is called the Eulerian method, and the other is the Lagrangian method. Eulerian focuses on specific locations in the space through which the fluid flows as time passes, while the Lagrangian follows an individual fluid parcel as it moves through space and time. Although the observing direction is opposite, there is no essential difference between those two methods, and the analytical results derived from them should be the same for the same problem. 
A decent mesh is essential for accurately calculating the pressure drop along pipeline, therefore, the hexahedral mesh was employed due to its good performance in easy convergence and time saving. Furthermore, in order to capture the flow properties close to pipe, inflation function was applied in the boundary layer (see Figure 4). And the independence of the grid has been verified though varying the grid density.

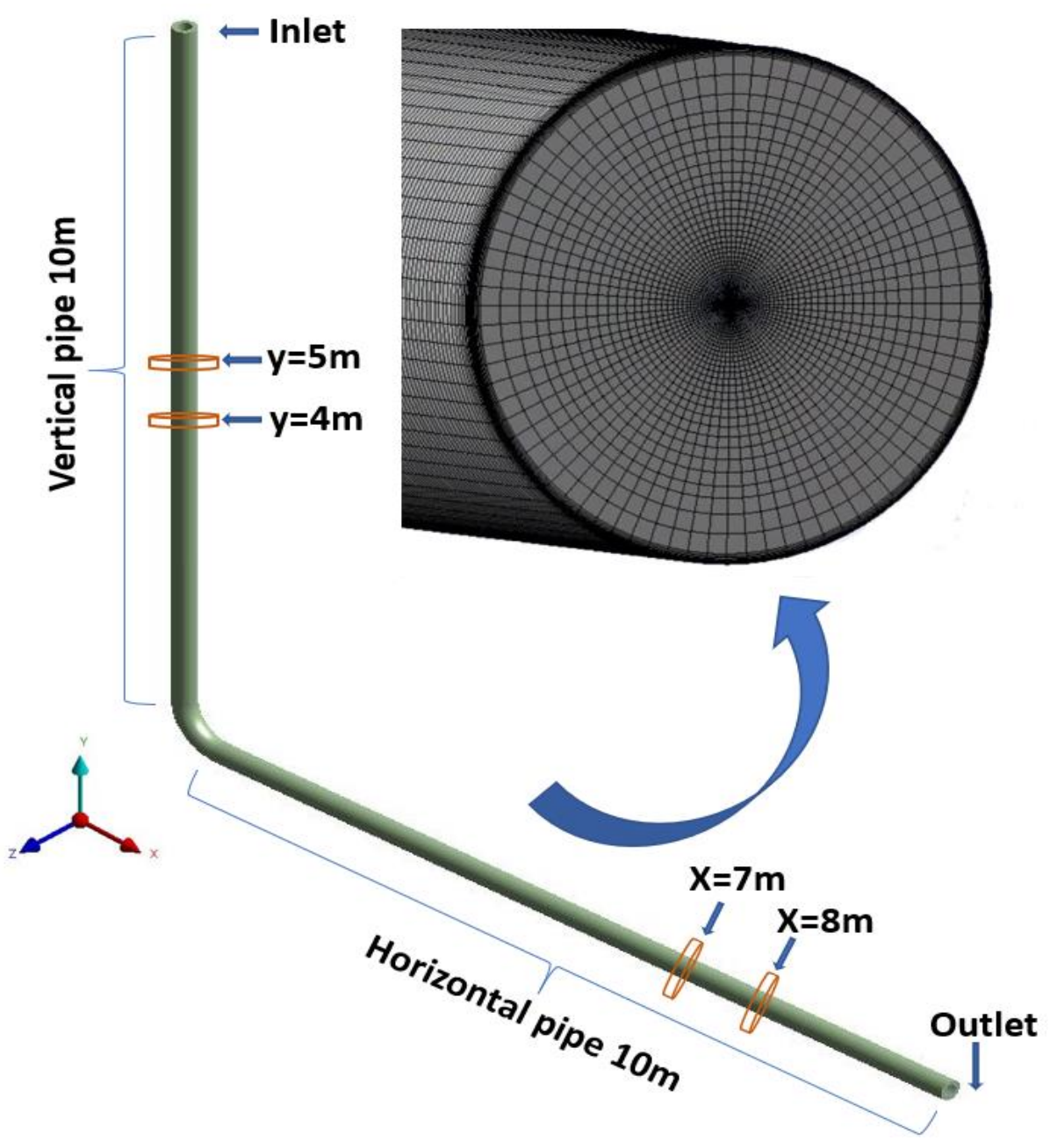

Figure 4. Mesh of the fluid domain

Due to the homogeneous continuous medium characteristics of the filling slurry, both Eulerian and Lagrangian methods are applicable in reconstructing the flow characteristics of the fluid domain. In the present paper, the Eulerian approach was adopted.

The following assumptions are made for the backfill slurry to save computational resources and simplify the numerical model: 
- The slurry flow in the pipe is continuous and flows smoothly;

- The mechanical properties of the slurry are uniform in all directions and make a homogeneous flow;

- The slurry is incompressible, and there is no heat exchange with the external environment during the delivery process.

The motion of the slurry flow in the pipeline was controlled by the governing equations, namely the mass conservation equation, momentum conservation equation, and energy conservation equation. By solving all the conservation equations in the fluid domain, the flow characteristics of the slurry in the pipe can be captured. Then through analyzing the collected data, some hidden rheological patterns can be unveiled. The mass conservation is written as equation 1.

$$
\frac{\partial \rho}{\partial t}+\operatorname{div}(\rho, \vec{v})=0
$$

Where $t$ is time, $\rho$ is the density of the slurry, and $v$ is the flow velocity of the fluid.

Due to the aforementioned incompressible flow assumption, the concentration of the slurry does not vary with time, so $\mathrm{eq}^{\mathrm{n}} 1$ can be rewritten in the following equation 2 form.

$$
\frac{\partial u}{\partial x}+\frac{\partial v}{\partial y}+\frac{\partial w}{\partial z}=0
$$

Where $\mathrm{u}, \mathrm{v}, \mathrm{w}$ is the velocity vector component in the $\mathrm{x}, \mathrm{y}, \mathrm{z}$-direction, respectively.

The slurry momentum conservation equation can be derived using Newton's second law, as shown in equation 3,4 , and 5 .

$$
\begin{aligned}
& \frac{\mathrm{du}}{\mathrm{dt}}=X-\frac{1}{\rho} \frac{\partial \mathrm{P}}{\partial \mathrm{x}}+\mu\left(\frac{\partial^{2} u}{\partial x^{2}}+\frac{\partial^{2} u}{\partial y^{2}}+\frac{\partial^{2} u}{\partial z^{2}}\right) \\
& \frac{\mathrm{dv}}{\mathrm{dt}}=Y-\frac{1}{\rho} \frac{\partial \mathrm{P}}{\partial \mathrm{y}}+\mu\left(\frac{\partial^{2} v}{\partial x^{2}}+\frac{\partial^{2} v}{\partial y^{2}}+\frac{\partial^{2} v}{\partial z^{2}}\right)
\end{aligned}
$$




$$
\frac{\mathrm{dw}}{\mathrm{dt}}=Z-\frac{1}{\rho} \frac{\partial \mathrm{P}}{\partial \mathrm{z}}+\mu\left(\frac{\partial^{2} w}{\partial x^{2}}+\frac{\partial^{2} w}{\partial y^{2}}+\frac{\partial^{2} w}{\partial z^{2}}\right)
$$

Where $\mathrm{X}, \mathrm{Y}, \mathrm{Z}$ represent the surface force of the fluid micro-element in $\mathrm{x}, \mathrm{y}, \mathrm{z}$ directions, respectively. P represents the combined force acting on the fluid micro-element, $\rho$ is the slurry density, and $\mu$ denotes the viscosity of the tested slurry. The meaning of other symbols is the same as that of equation 2 .

The flow of the slurry in the pipe follows the law of conservation of energy and assumes that there is no exchange of heat with the external environment. Hence, the Bernoulli equation for the fluid can be written in the following form:

$$
z_{1}+\frac{P_{1}}{\gamma}+\frac{V_{1}^{2}}{2 g}=z_{2}+\frac{P_{2}}{\gamma}+\frac{V_{2}^{2}}{2 g}+H
$$

Where $\mathrm{Z1}, \mathrm{Z} 2$ represents the spatial position of the fluid micro-element in the pipe, respectively, while $\mathrm{P} 1$ and $\mathrm{P} 2$ are the pressure corresponding to the $\mathrm{Z} 1$ and $\mathrm{Z} 2$ position. V1 and V2 are the flow velocity at positions Z1 and Z2. $\gamma$ is the bulk density, and H delegates the work done by the pipe friction force on the slurry when it flows from position $\mathrm{Z} 1$ to $\mathrm{Z} 2$.

Table 2. Model setting

\begin{tabular}{lcc}
\hline Concentrate (\%) & Velocity $(\mathrm{m} / \mathrm{s})$ & Diameter $(\mathrm{m})$ \\
\hline \multirow{3}{*}{76} & 2.0 & \\
& 2.5 & \\
& 3.0 & 0.15 \\
77 & 2.0 & 0.18 \\
& 2.5 & 0.21 \\
78 & 3.0 & \\
\cline { 2 - 3 } 78 & 2.0 & \\
& 2.5 & \\
\hline
\end{tabular}

To comprehensively investigate the influence of factors on pressure drop along the pipeline and how each element affects pressure drop in the slurry transport process, 27 sets of 
simulations with three main factors and three levels were carried out on the computational fluid software ANSYS. The portfolio of investigated involved is presented in Table 2.

An appropriate discretization is a foundation for the subsequent simulation. Therefore, it is vital to have a fine mesh for the targeted computational domain, especially for the region with a complex shape (in the present bend section). Therefore, a finer mesh was deployed in the bend to capture the features of slurry flowing through the turn.

The boundary condition for the inlet was velocity inlet with three levels. The outlet was set to be a pressure outlet with zero static pressure and the gravity force along the opposite direction of the Y coordinate axis.

\section{Results and discuss}

\subsection{Single factor analysis}

\subsubsection{Influence of flow velocity on pressure drop}

It can be seen from Figure 5 that the pressure-drop of all the investigated concentration-diameter-position combinations increase gradually concerning the increasing slurry velocity when the pipe diameter is $0.15 \mathrm{~m}$, although the increased speed of the pressure drop varies from each variety. For instance, the growth rate of the pressure-drop of the combination W77D15B (The two digits after W indicate the concentration of the slurry, the two digits after $\mathrm{D}$ indicate the diameter of the pipe in centimeters, the last letter indicates the different pipe parts, and $\mathrm{V}$ represents the vertical part $\mathrm{H}$ represents the horizontal part $\mathrm{B}$ represents the bent pipe part. For example, W77D15B means that the slurry with 77\% concentration flows through the bent portion of the pipe with a diameter of $15 \mathrm{~cm}$. The following combinations in this paper follow the same naming rules, W78D15V, W78D15B, and W78D15H decrease with increasing flow speed. However, for slurries W76D15H, 
W76D15V and W76D15B, the opposite is the case.

Additionally, this diagram shows another distinctive feature: different parts of the pipe exhibit additional pressure losses under the influence of flow velocity. For example, when the solid concentration is $77 \%$, pressure drops much more at the bend section of the pipe than the corresponding vertical or horizontal section for all velocity. The other two groups (namely $76 \%$ concentration group and $78 \%$ concentration group) also showed the same characteristics. More specifically, the descending order of pressure drop within each concentration group is bend section, vertical section, and horizontal section.

Figure 6 depicts the pressure drop gradient of the slurries with flow velocity when the pipe diameter is $0.18 \mathrm{~m}$. This graph shows that pressure loss increases with increasing speed in all investigated combinations, except for W78D18B and W78D18H. In the case of W78D18B, as the flow rate increases, the increase in pressure loss is gradually slowing down. While for the slurry combination $\mathrm{W} 78 \mathrm{D} 18 \mathrm{H}$, the pressure loss per meter remains almost constant when the flow velocity exceeds $2.5 \mathrm{~m} / \mathrm{s}$. When comparing with Figure 5 , the most significant difference in Figure 6 is that the $78 \%$ concentration group slurry consumes more pressure at horizontal section than vertical section as the slurry flows below $2.5 \mathrm{~m} / \mathrm{s}$.

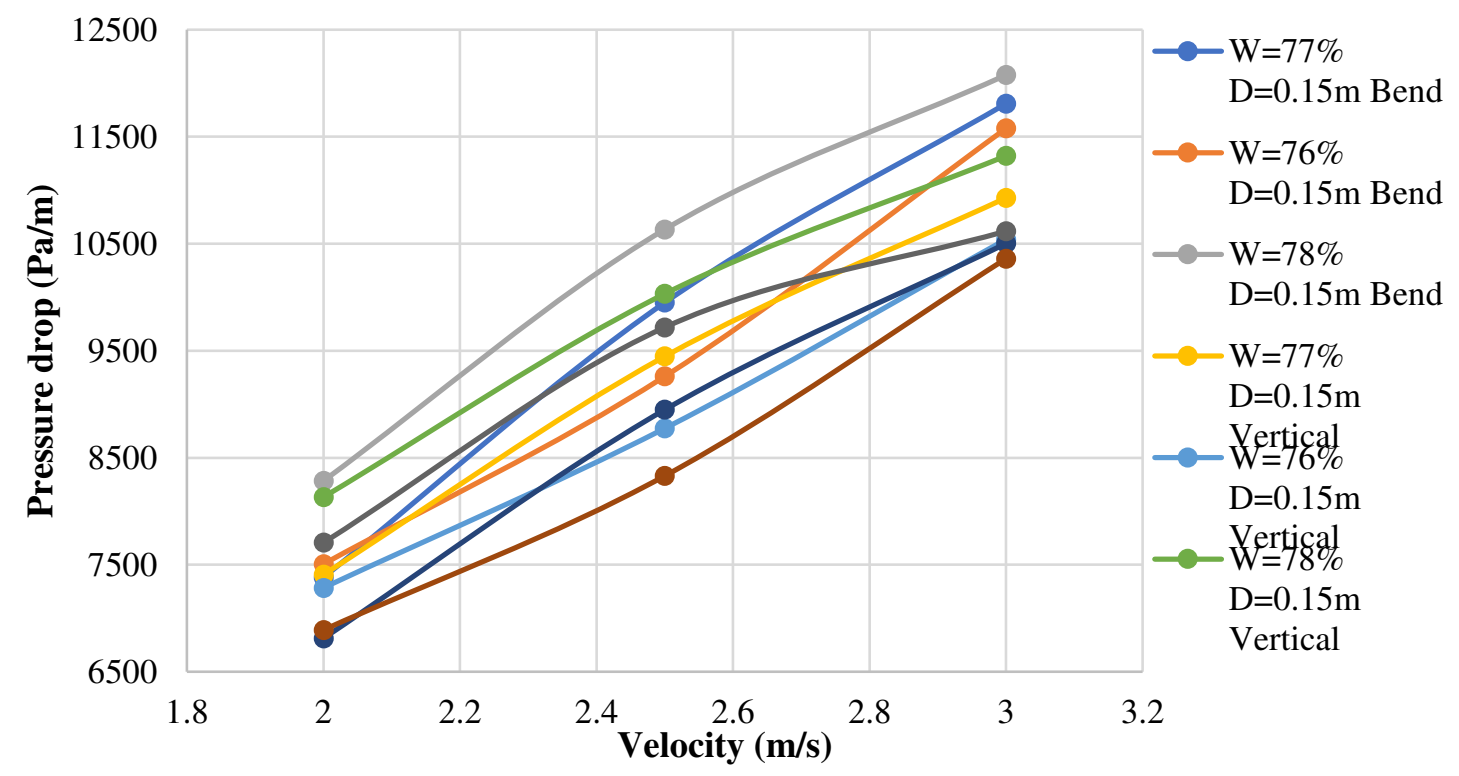

Figure 5. Pressure drop gradient with velocity when diameter equals $0.15 \mathrm{~m}$ 


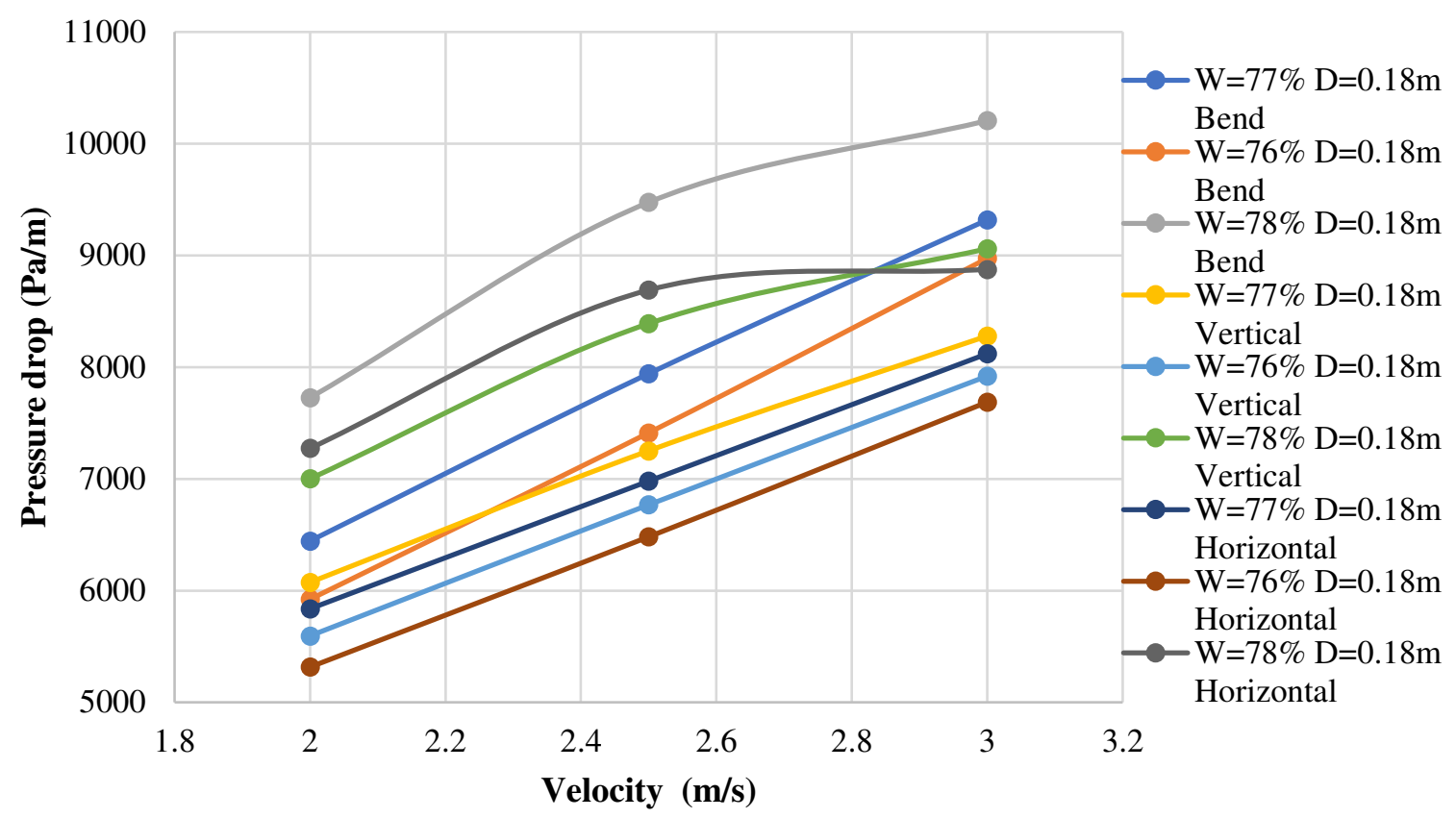

Figure 6. Pressure drop gradient with velocity when diameter equals $0.18 \mathrm{~m}$

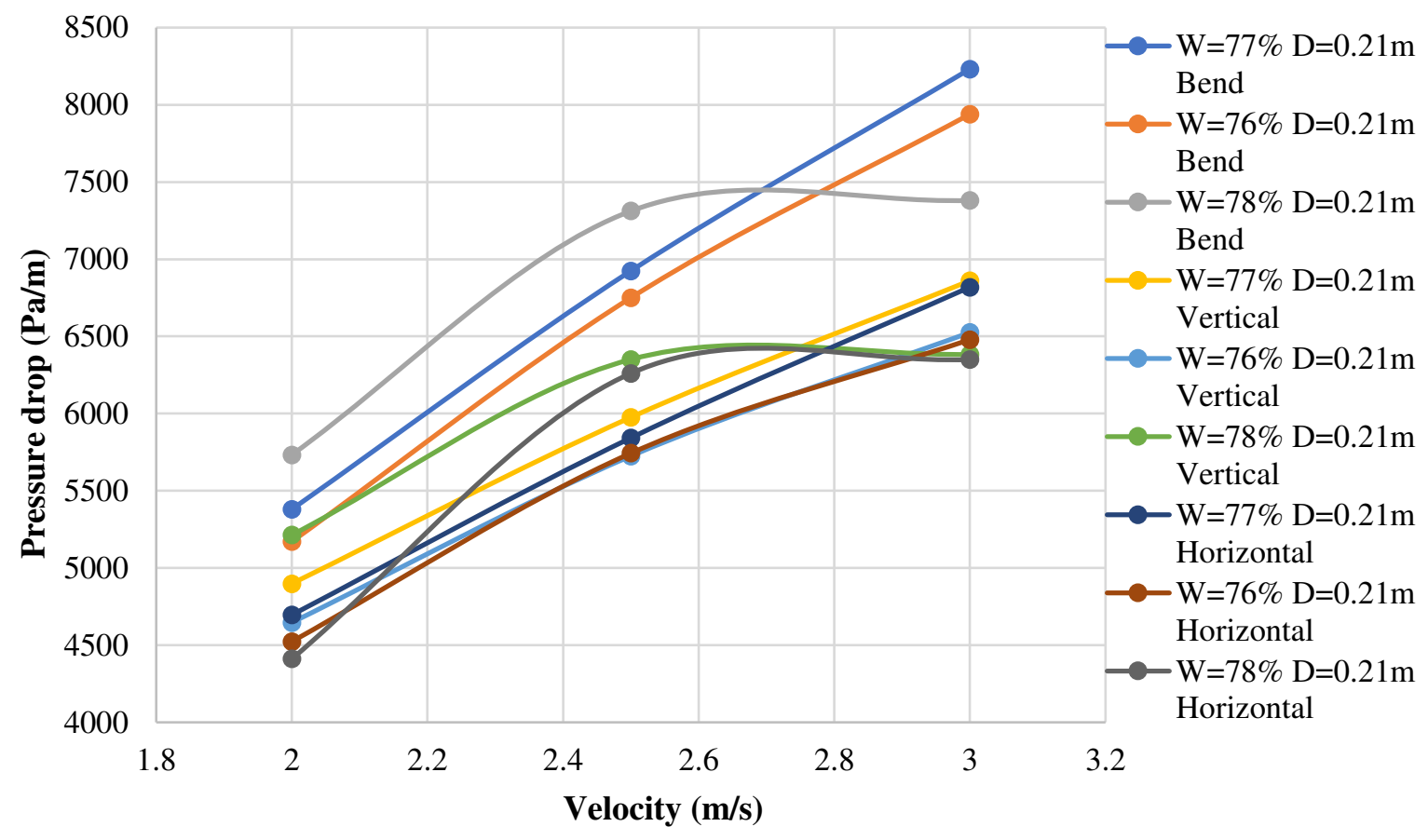

Figure 7. Pressure drop gradient with velocity when diameter equals $0.21 \mathrm{~m}$

Figure 7 illustrates how the pressure changes along with the varying flow velocity in a pipe with a $0.21 \mathrm{~m}$ diameter. This chart demonstrates a vast difference compared with the slurry flows in a $0.18 \mathrm{~m}$-diameter pipe (see Fig. 6) or a $0.15 \mathrm{~m}$-diameter pipe (see Fig. 5). The pressure drop gradient in the bend section of the slurry of 78\% concentration is not the largest among all the investigated slurry combinations. At a speed of $3 \mathrm{~m} / \mathrm{s}$, the pressure drop 
gradient in the bend section of slurry W78D21B is less than that of the corresponding slurries W77D21B and W76D21B. The pressure drop of the slurry in the 78\% concentration group generally remains stable when the flow velocity exceeds $2.5 \mathrm{~m} / \mathrm{s}$. At the same time, the pressure-drop of $77 \%$ and the $76 \%$ concentration group experienced a steady increase.

The above phenomena show that velocity is not the only factor affecting pressure drop and that velocity acts differently in different parts (bend, vertical and horizontal section) of the pipe.

When the solid concentration is $76 \%$, the pressure drop increases linearly with an increasing velocity at all the pipe sections (namely bend, vertical and horizontal). In contrast, the pressure drop of the slurry with a concentration of $78 \%$ grows progressively slower at the bend section of the pipe. It reflects that when slurry flows velocity increases, its influence on pressure loss declines compared with the slurries in $77 \%$ and $76 \%$ concentration. The pressure loss disparity between slurries with a concentration of $78 \%, 77 \%$, and $76 \%$ is depicted in Figures 6 and 7. Those two charts demonstrate that when delivering slurry in a pipe with a $0.18 \mathrm{~m}$ diameter, the higher the slurry concentration, the more significant the pressure drop. In addition to the slurry concentration, the flow velocity has a considerable influence on the pressure drop disparities among different test groups.

The gap in pressure drop between the two groups of slurries with a solid concentration of $78 \%$ and $77 \%$ is most significant at a flow velocity of $2.5 \mathrm{~m} / \mathrm{s}$ in all pipe sections. And the minimum pressure drop gap occurs when the slurry flows velocity is $3 \mathrm{~m} / \mathrm{s}$ (see Fig. 6).

However, the changing tendency of the pressure drop gap between slurries of $77 \%$ solid concentration and $76 \%$ solid concentration appears remarkably different. When the flow speed rises from $2 \mathrm{~m} / \mathrm{s}$ to $2.5 \mathrm{~m} / \mathrm{s}$, the pressure drop gap almost remains stable no matter which part of the pipe the slurry flows. In comparison, the pressure drop disparity decreases sharply as the flow velocity increases from $2.5 \mathrm{~m} / \mathrm{s}$ to $3 \mathrm{~m} / \mathrm{s}$ (see Fig. 7). 


\subsubsection{Influence of solid concentration on pressure drop}

Slurry concentration is a decisive consideration in the preparation of slurry, and it dominates the strength development of the backfill mass. This section focuses on the effect of slurry concentration on pressure drop in different pipe sections.

Figure 8 exhibits the effect of different slurry concentrations on the pressure drop of the slurry flowing through other parts of the pipe with a $0.18 \mathrm{~m}$ diameter. All the curves in the graph show that the pressure drop increases with increasing concentration and accelerates at concentrations above $77 \%$. The pressure disparities between different concentration groups at a separate pipe section were depicted in Figures $9 \& 10$. It clearly illustrates that the change of slurry concentration has an evident influence on the pressure drop and the scale of this influence is dependent on which part of the pipe the slurry is flowing by. For example, when the flow velocity is $2 \mathrm{~m} / \mathrm{s}$, the pressure drop gap between slurries with a concentration of $78 \%$ and $77 \%$ at the horizontal section is the largest. On the other hand, the slightest pressure drop gap appears at the vertical section of the pipe. At a flow velocity of $3 \mathrm{~m} / \mathrm{s}$, the difference in pressure drop in the bend section is slightly greater than in the horizontal and vertical areas (see Fig. 8).

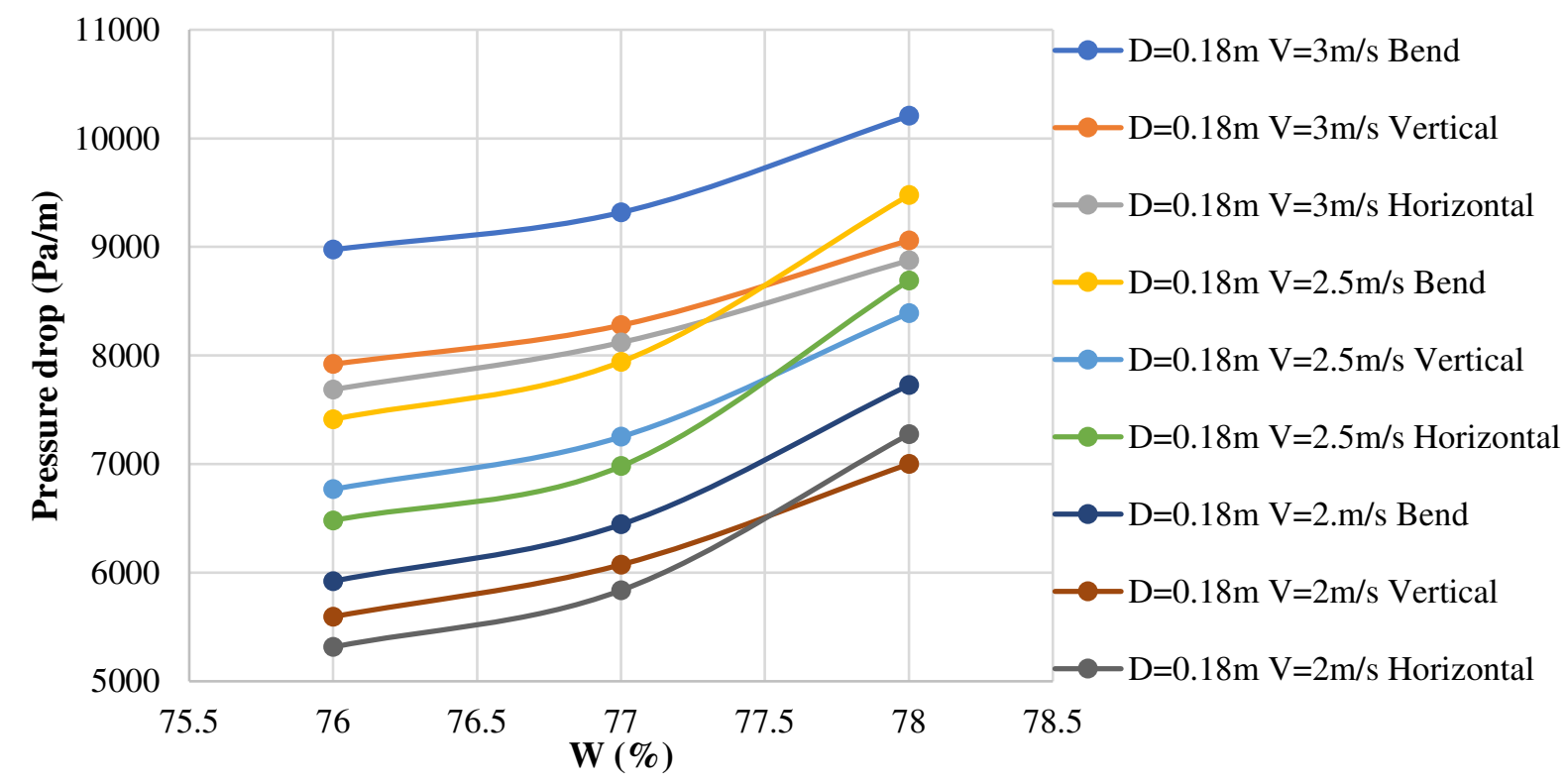

Figure 8. Pressure drop gradient with concentration when diameter equals $0.18 \mathrm{~m}$ 
When the flow velocity is below $2.5 \mathrm{~m} / \mathrm{s}$, the change tendency of the pressure drop disparity between slurries with the concentration of $77 \%$ and $76 \%$ is similar to that of slurries with a concentration of $78 \%$ and $77 \%$, except the corresponding pressure drop gaps are somewhat narrower (see Fig. 8 and Fig. 9). However, as shown in Figure 9, when the flow velocity reaches $3 \mathrm{~m} / \mathrm{s}$, the pressure drop difference between slurry in concentration $77 \%$ and slurry in concentration $76 \%$ at bend section becomes the least significant.

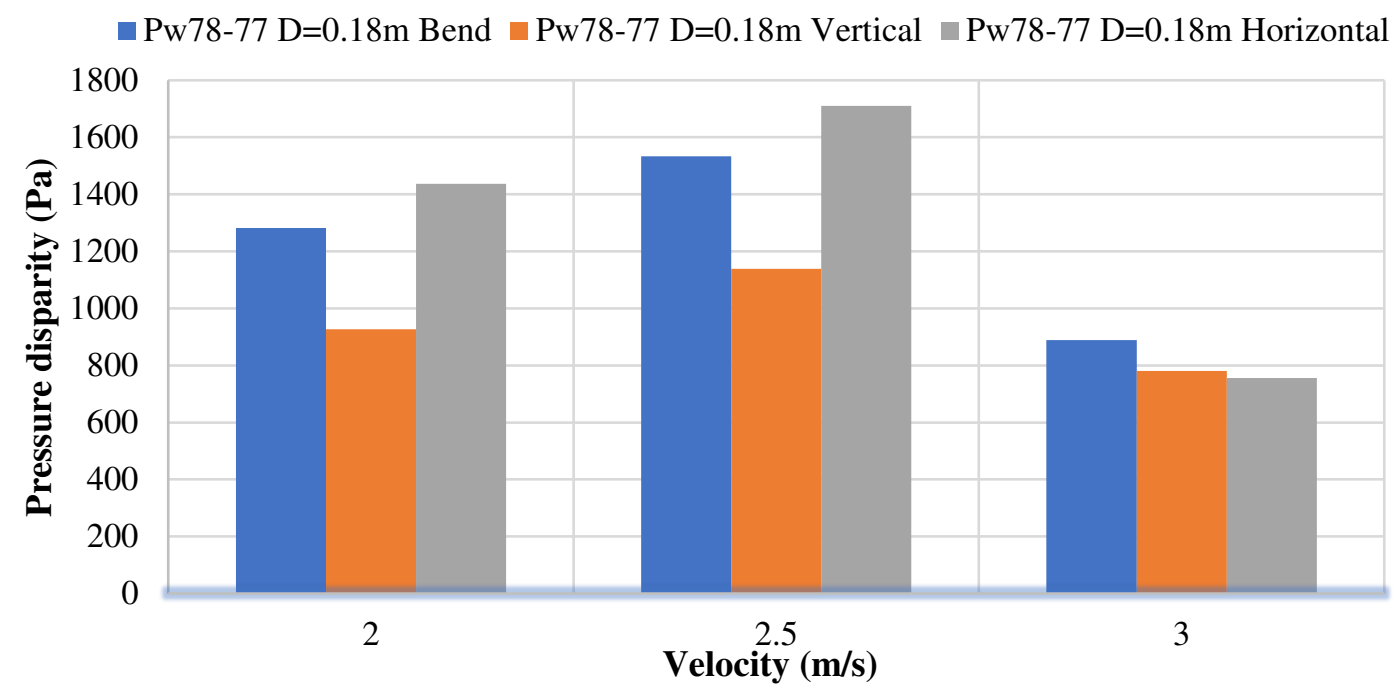

Figure 9. Pressure drop disparity between slurry Pw78 and Pw77 when the diameter is $0.18 \mathrm{~m}$

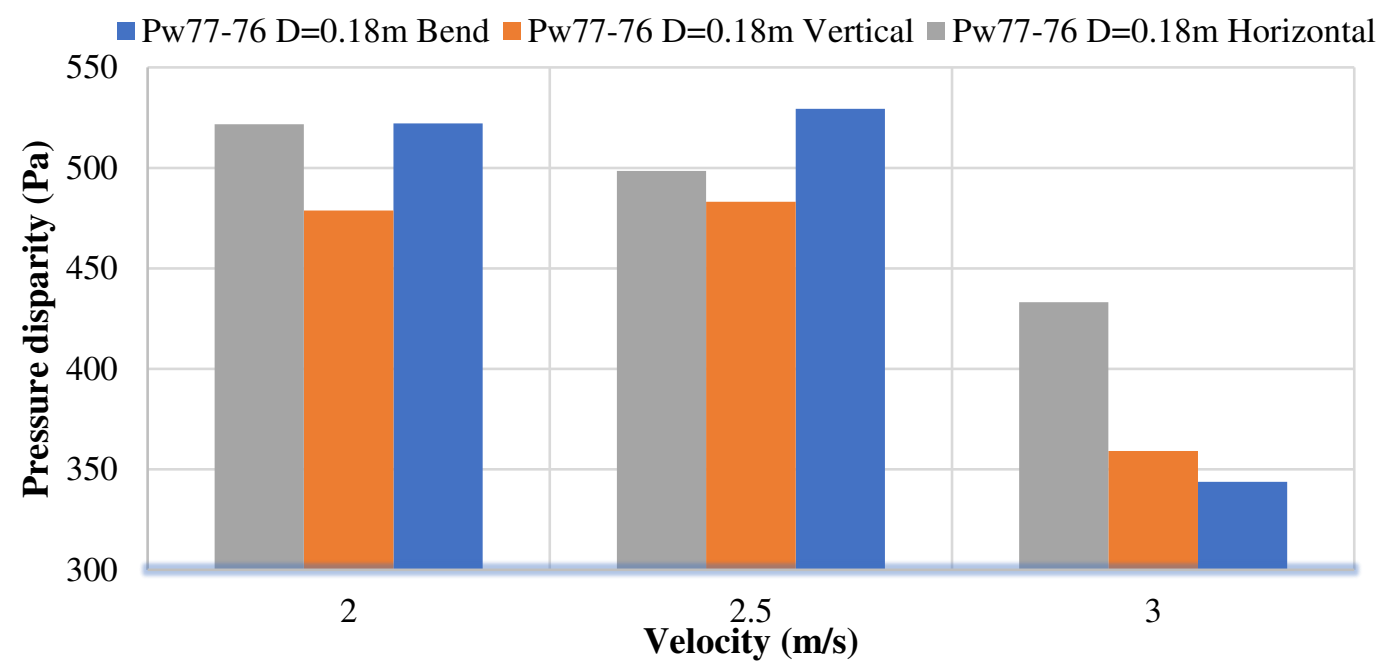

Figure 10. Pressure drop disparity between slurry Pw77 and Pw76 when the diameter is $0.18 \mathrm{~m}$

The gradually increasing tendency of pressure-drop with a rising velocity of the slurries for all investigated groups is generally similar when the pipe diameter is $0.18 \mathrm{~m}$. In 
contrast, the growth speed of the pressure drop varies from each other. For instance, when the solid concentration is $76 \%$, the pressure-drop increases linearly with an increasing velocity at all the pipe sections (namely bend, vertical and horizontal). However, at the bend section of the pipe, the pressure drop shows a more significant rise than vertical and horizontal parts.

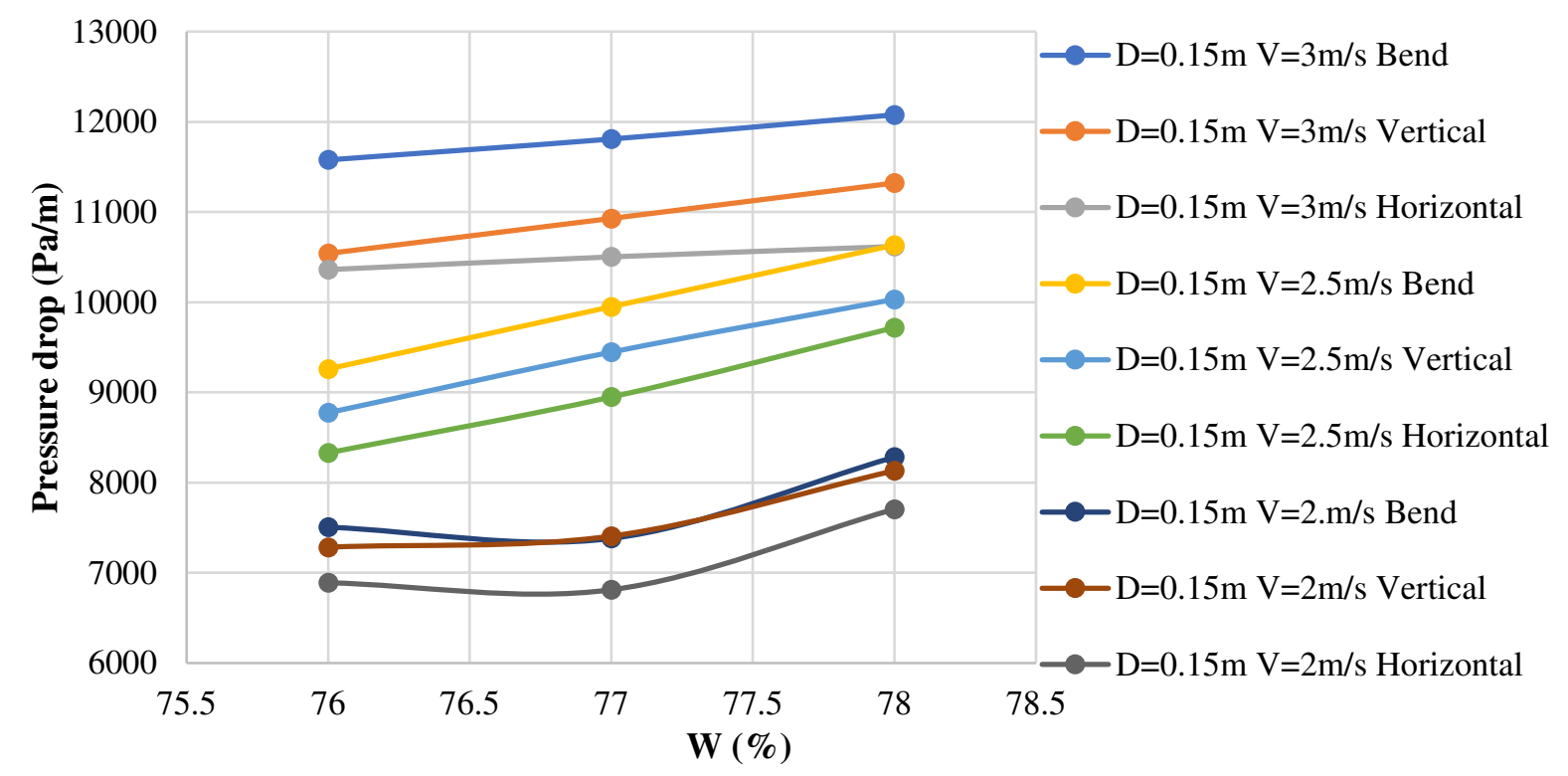

Figure 11. Pressure drop gradient with concentration when diameter equals $0.15 \mathrm{~m}$

As shown in figure 11, most of the investigated slurry combinations follow the pattern of increasing pressure drop with growing concentration except for slurry W77D15B and W77D15H. This unusual variation is illustrated more clearly in Figures 12 and Figure 13. The pressure drop disparities in all sections of the pipeline are all positive, indicating that the $78 \%$ concentration slurry does indeed lose more pressure than the $77 \%$ concentration slurry, despite the different pressure drop gaps in the corresponding sections of the pipeline (see Fig. 12). However, when the slurry flows $2 \mathrm{~m} / \mathrm{s}$ in the bend and horizontal area of the pipe, the slurry with a concentration of $77 \%$ has less pressure reduction than the slurry with $76 \%$ (see Fig. 13). The reason behind this anomaly is likely to be the superimposition of expected effects of pipe diameter, slurry velocity, and concentration. 


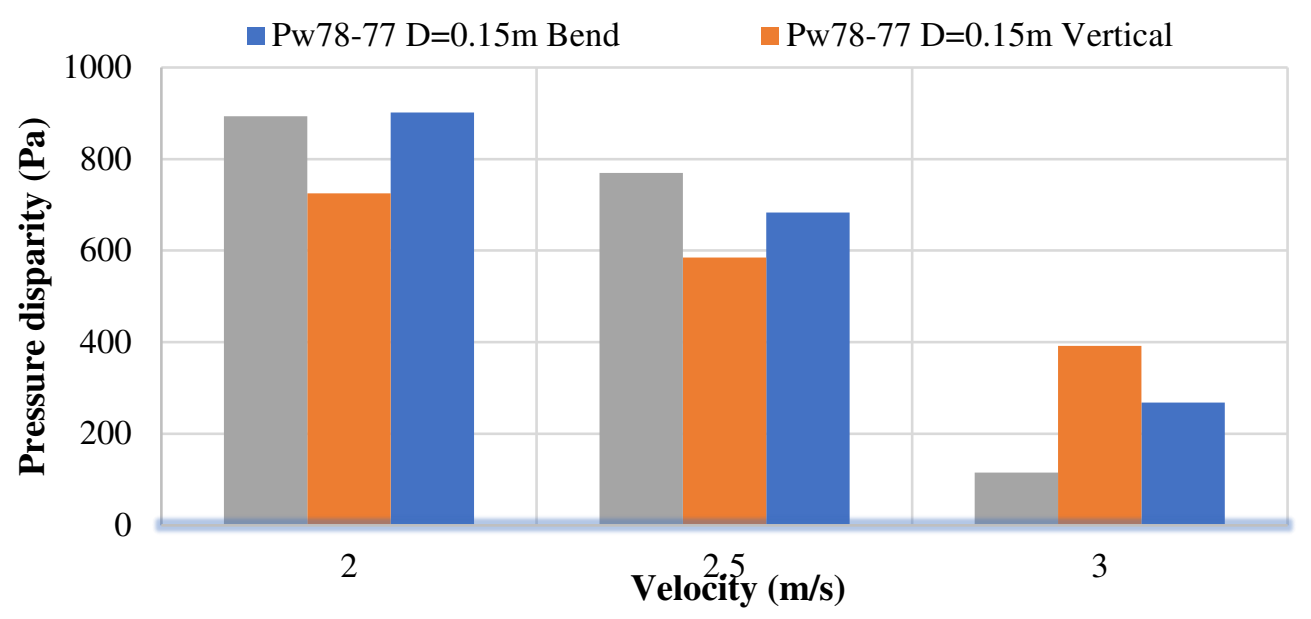

Figure 12. Pressure drop disparity between slurry Pw78 and Pw77 when the diameter is $0.15 \mathrm{~m}$

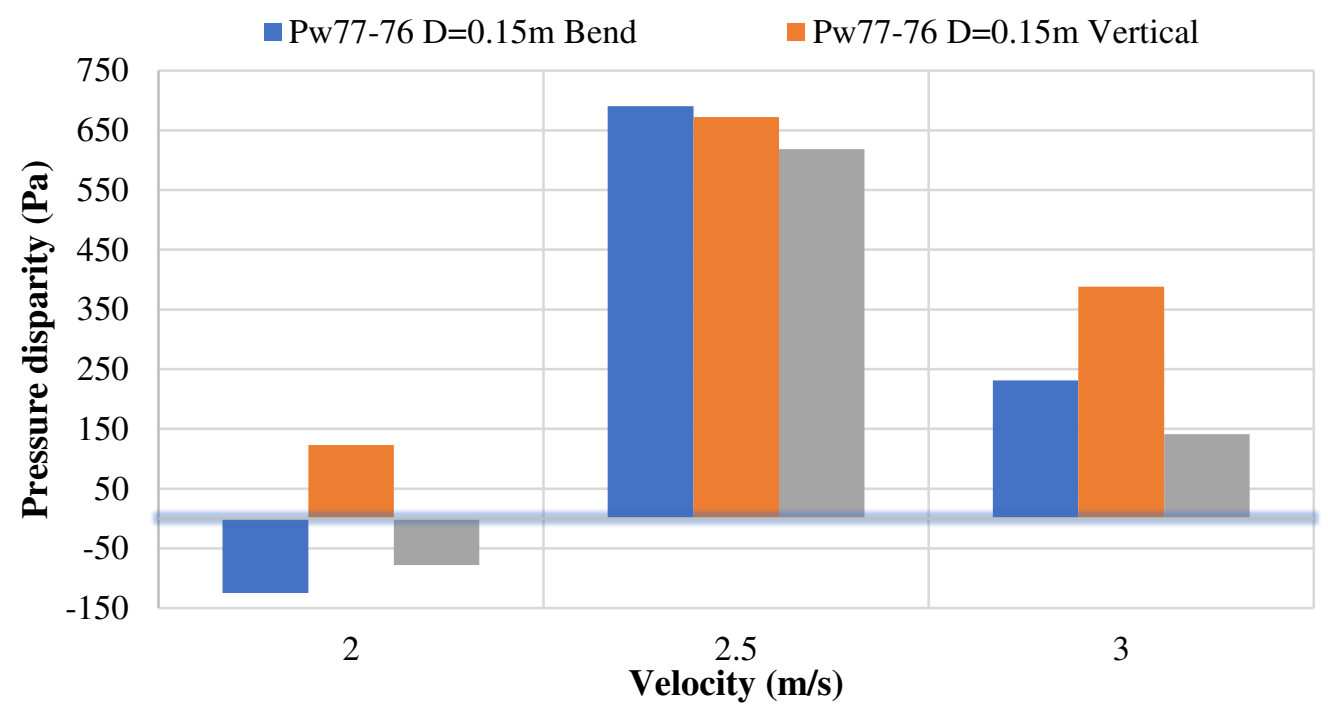

Figure 13. Pressure drop disparity between slurry Pw77 and Pw76 when the diameter is $0.15 \mathrm{~m}$

If comparing Figure 14 with Figures 11 and 8, it is easy to notice that as the concentration rises, the pressure loss of the slurry in the larger diameter pipes is substantially different from that in, the smaller diameter pipes. For example, the pressure drop of all the slurry combinations as the solid concentration increases from $76 \%$ to $77 \%$. However, when the concentrate continues to grow to $78 \%$, some varieties of pressure drop are reduced conversely (see Fig. 14). 


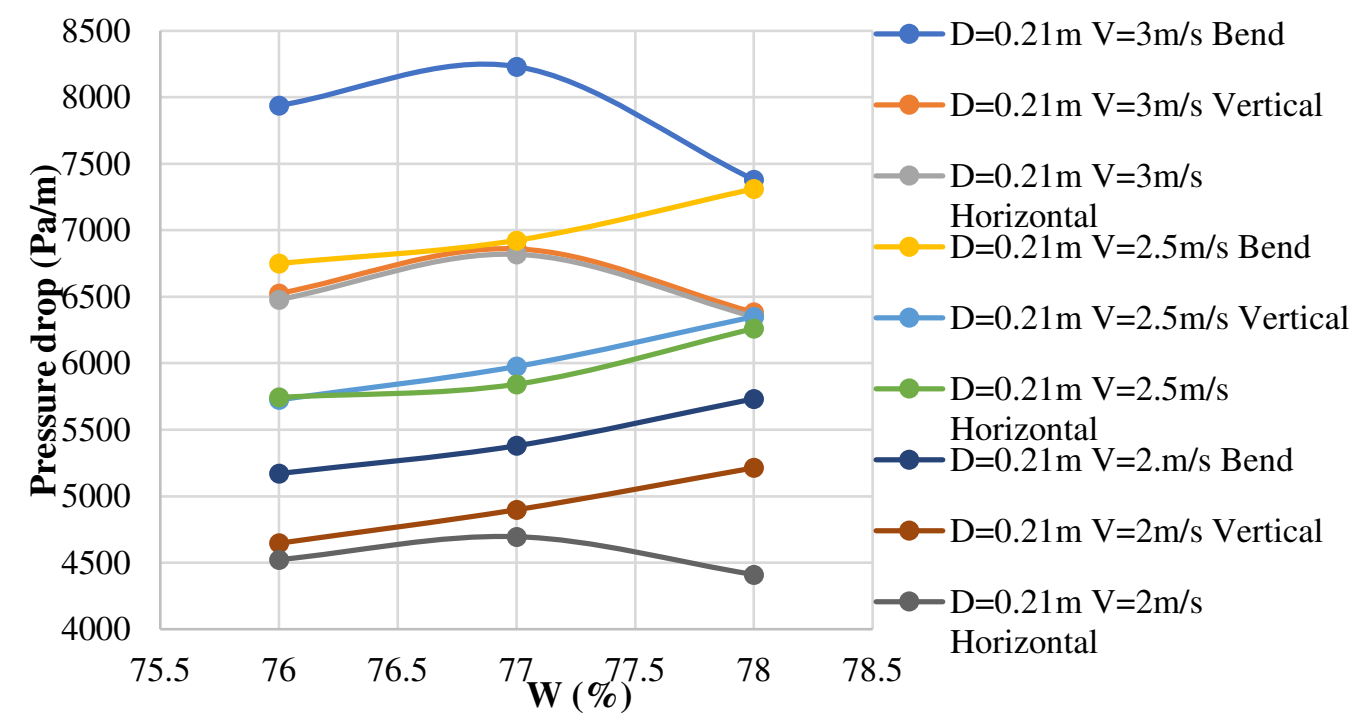

Figure 14. Pressure drop gradient with concentration when diameter equals $0.21 \mathrm{~m}$

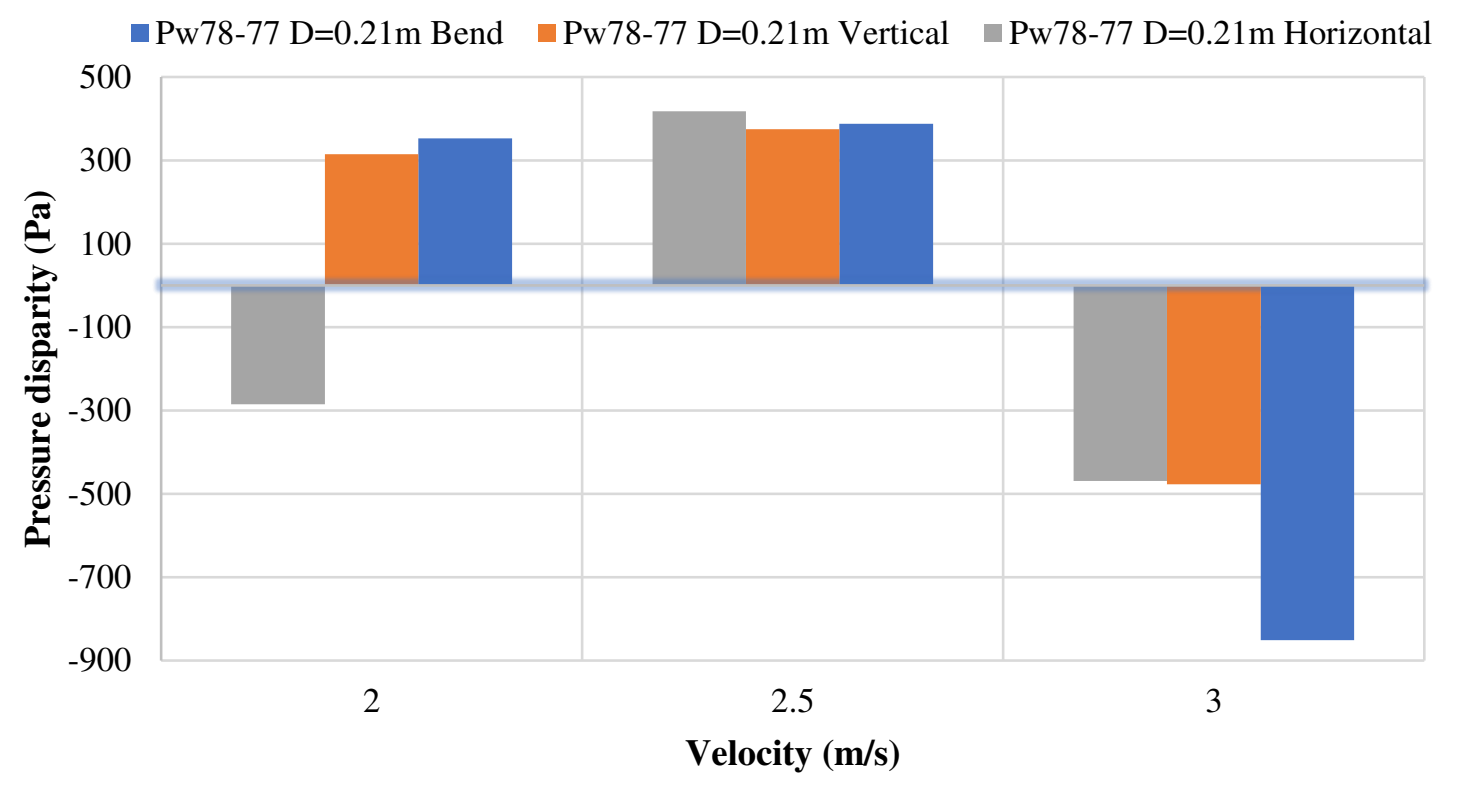

Figure 15. Pressure drop disparity between slurry Pw78 and Pw77 when the diameter is $0.21 \mathrm{~m}$

Figure 15. reflects the gap of pressure drop between slurries with the concentration of $77 \%$ and $78 \%$. When the velocity is $3 \mathrm{~m} / \mathrm{s}$, the slurry with $78 \%$ concentration loses less pressure than the slurry with $77 \%$ concentration, both in the vertical and horizontal sections and elbow sections. And at the bend section, the slurry with $78 \%$ concentration also consumes less pressure than slurry with $77 \%$ concentrate when the velocity is $2 \mathrm{~m} / \mathrm{s}$. This negative 
pressure drop may be that the diameter of the pipe plays a dominant role in such conditions compared to the concentration and rate.

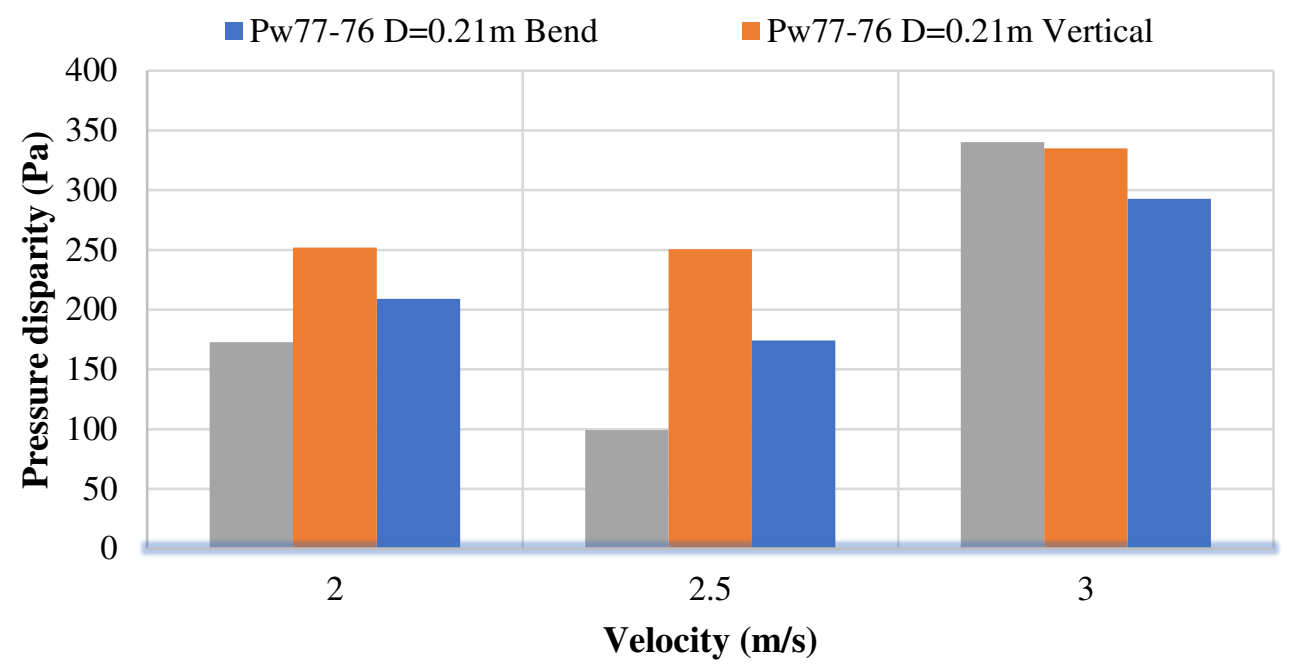

Figure 16. Pressure drop disparity between slurry Pw77 and Pw76 when the diameter is $0.21 \mathrm{~m}$

The positive values shown in Figure 16 indicate that more energy is required to provide sufficient pressure to transport a high concentration slurry than a low concentration slurry. The phenomenon is consistent with what is demonstrated in Figure 14.

\subsubsection{Influence of pipe diameter on pressure drop}

Figures 17, 18 and 19 reproduced how the pressure drops under changing pipe diameter. It is evident from these three charts, and the increasing pipe diameter will definitely facilitate the reduction of pressure loss and thus save energy needed for transmission. The $76 \%$ concentrate slurry and $77 \%$ concentrate slurry group showed a strong regularity. In the velocity subgroups, the pressure drop from highest to lowest is bend, vertical and horizontal section (see Fig. 17 and 18). However, in terms of the $78 \%$ concentration slurry group, it becomes more complex. A comparison with Figures 17 and 18 reveals that the most obvious difference is that all the curves in Figure 19 are convex in shape. That implies that when the slurry concentration is $78 \%$, the pressure drop decreases genteelly in the lower diameter 
range. On the other hand, the pressure drop reveals a relatively sharp decline in the higher diameter range. Therefore, $0.18 \mathrm{~m}$ is the inflection point of pipe diameter, which deserves special attention when designing the pipeline system for conveying slurries.

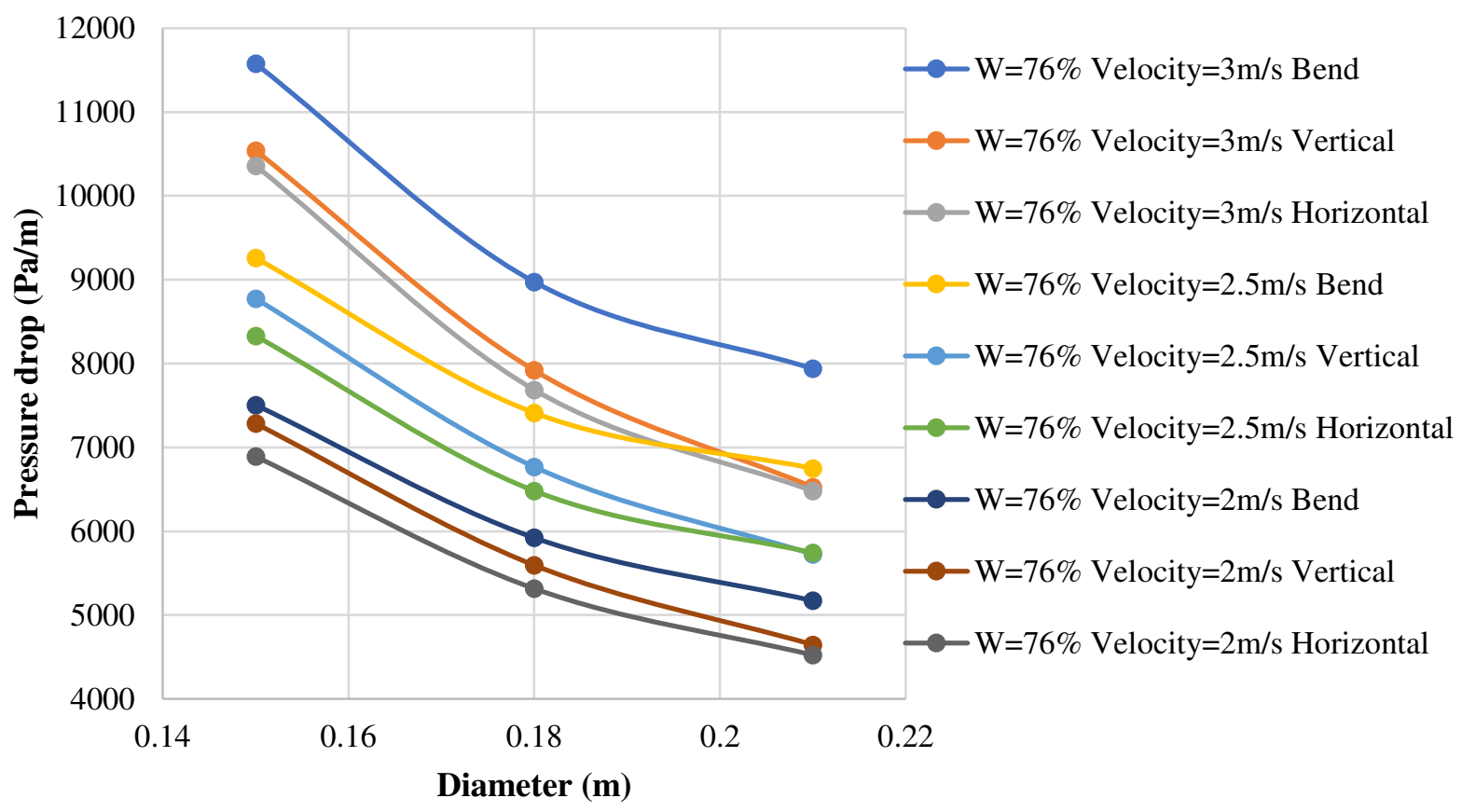

Figure 17. Pressure drop gradient with diameter when concentrate equals $76 \%$

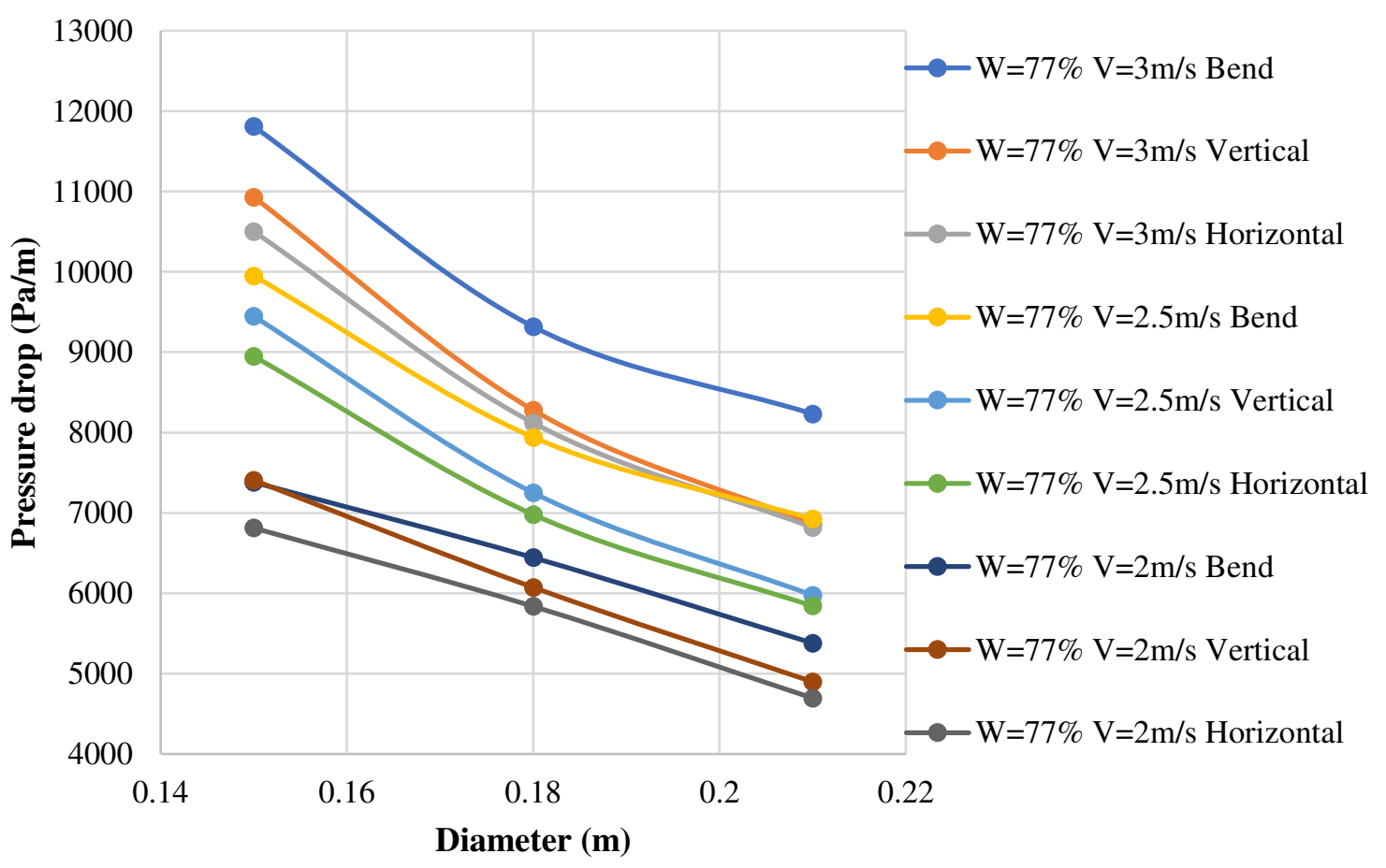

Figure 18. Pressure drop gradient with diameter when concentrate equals $77 \%$ 


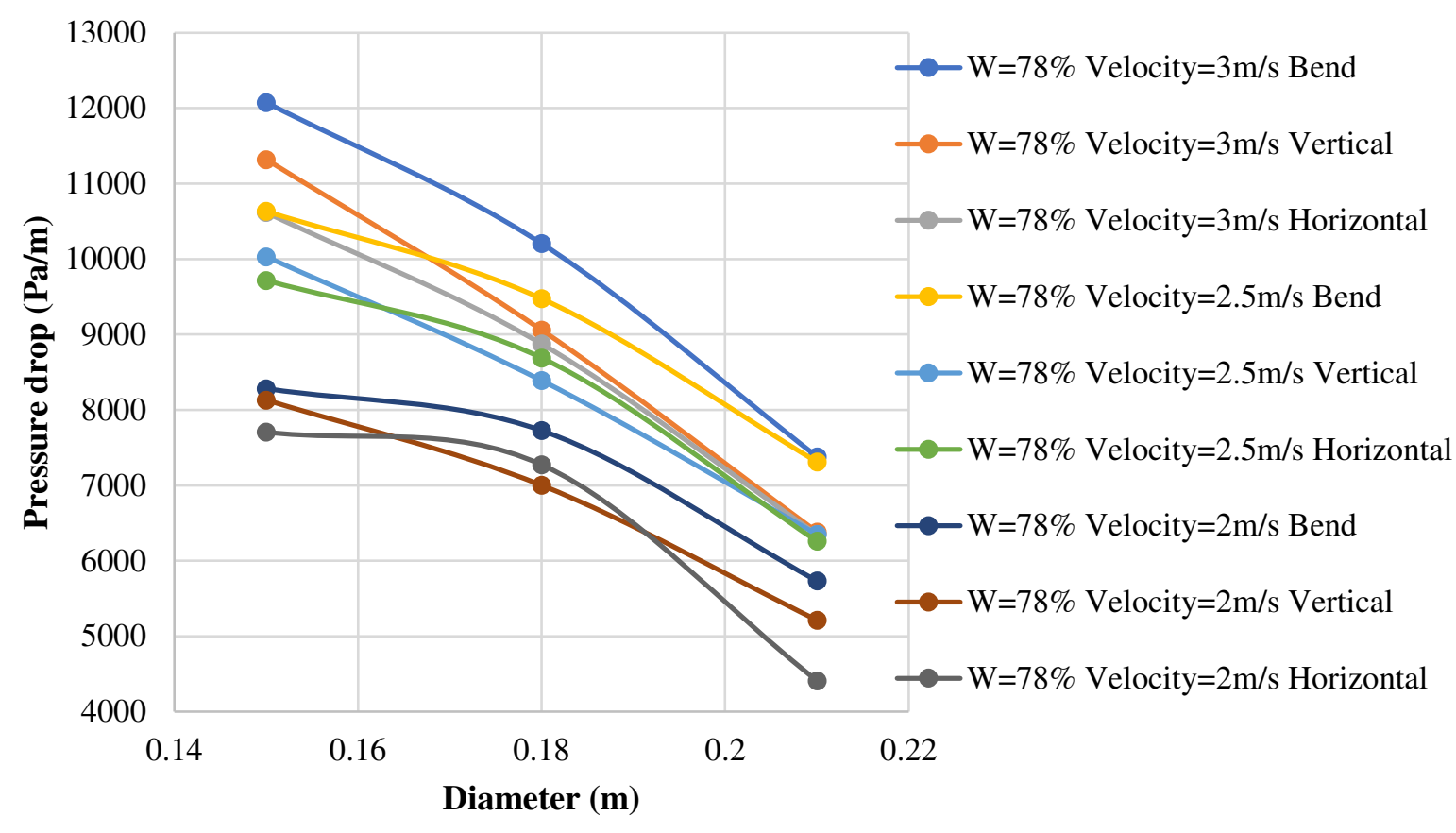

Figure 19. Pressure drop gradient with diameter when concentrate equals $78 \%$

\subsection{Multi-factor response surface analysis}

From the above analysis, we can clarify that pressure drop is the result of many factors acting together. Therefore, to understand the law of pressure loss, we must consider all the elements comprehensively. However, it is unrealistic or costly to consider all influences, and some individual consequences are relatively minor under certain conditions and can be disregarded for the time being. Therefore, the most scientific approach is to identify which influences have a greater or lesser weighting. Therefore, response surface methodology was adopted, and a professional software named Design expert was run to determine the weights of slurry concentration, flow rate, and pipe diameter on pressure losses in different pipe sections (Stat-Ease Inc.).

Response surface methodology (Yusri et al., 2018) is a collection of mathematical and statistical techniques that can analyze all the dominant factors and influence the dependence variable (Kazeem et al., 2018). A central composite design with three independent variables (namely the pipe diameter, slurry velocity, and concentration) at three levels was performed by applying the Design Expert 12. 
After 60 runs in total, the fit summary of different fitting models' accuracy and practicality at the bend section, vertical section, and horizontal section are listed in Table 2 , Table 3, and table 4. From which, the most suitable model was automatically presented. As for the bend and vertical parts of the pipe, the 2FI model is suggested, while the linear model is recommended for the horizontal section. Given that the $2 \mathrm{FI}$ model is inferior to the linear model only in the Predicted R2 and the consistency with the vertical and bend section, all the following analyses were based on the 2FI model. Finally, the general form of the 2FI model is demonstrated as equation 7 .

Table 3. Comparison of different models at bend section

\begin{tabular}{lllll}
\hline Source & \multicolumn{4}{l}{ Sequential $\mathbf{p}$-value Lack of Fit $\mathbf{p}$-value Adjusted $\mathbf{R}^{\mathbf{2}}$ Predicted $\mathbf{R}^{\mathbf{2}}$} \\
\hline Linear & $<0.0001$ & 0.9117 & 0.8567 & \\
$\mathbf{2 F I}$ & $\mathbf{0 . 0 3 3 2}$ & $\mathbf{0 . 9 4 3 2}$ & $\mathbf{0 . 8 6 5 7}$ & Suggested \\
Quadratic & 0.3479 & 0.9461 & 0.7673 & \\
Cubic & 0.0074 & 0.9886 & -3.4145 & Aliased \\
\hline
\end{tabular}

Table 4. Comparison of different models at vertical section

\begin{tabular}{lllll}
\hline Source & \multicolumn{4}{c}{ Sequential $\mathbf{p}$-value Lack of Fit $\mathbf{p}$-value Adjusted $\mathbf{R}^{\mathbf{2}}$ Predicted $\mathbf{R}^{\mathbf{2}}$} \\
\hline Linear & $<0.0001$ & 0.9330 & 0.8856 & \\
$\mathbf{2 F I}$ & $\mathbf{0 . 0 0 6 4}$ & $\mathbf{0 . 9 6 7 0}$ & $\mathbf{0 . 9 2 0 9}$ & Suggested \\
Quadratic & 0.1265 & 0.9752 & 0.8891 & \\
Cubic & 0.0097 & 0.9942 & -1.2409 & Aliased \\
\hline
\end{tabular}

Table 5. Comparison of different models at the horizontal section

\begin{tabular}{lllll}
\hline Source & \multicolumn{4}{c}{ Sequential $p$-value Lack of Fit $\mathbf{p}$-value Adjusted $\mathbf{R}^{\mathbf{2}}$ Predicted $\mathbf{R}^{\mathbf{2}}$} \\
\hline Linear & $<\mathbf{0 . 0 0 0 1}$ & $\mathbf{0 . 9 1 5 3}$ & $\mathbf{0 . 8 7 4 0}$ & Suggested \\
2FI & 0.1933 & 0.9265 & 0.8407 & \\
Quadratic & 0.5673 & 0.9213 & 0.6889 & \\
Cubic & 0.0119 & 0.9803 & -6.6249 & Aliased \\
\hline
\end{tabular}




$$
Y=B_{0}+\sum_{i=1}^{n} B_{i} X_{i}+\sum_{i=1}^{n-1} \sum_{j=i+1}^{n} B_{i j} X_{i} X_{j}+\epsilon
$$

Where $\mathrm{Y}$ is the dependent response, $\mathrm{B} 0$ is the constant coefficient, $B_{i}$ is the linear coefficient and $B_{i j}$ is the interaction coefficient, $\mathrm{n}$ is the number of factors investigated in the present paper, while the term $X_{i}$ and $X_{i} X_{j}$ are the independent variables and the interactions, respectively. The $\epsilon$ represents the random error.

\subsubsection{Response surface analysis at a vertical section}

From table 6, it can be seen that the Model F-value is 42.25, which implies the model is significant in the vertical section. There is only a $0.01 \%$ chance that this large F-value could occur due to noise. P-values less than 0.05 indicate model terms are significant. In this case, velocity, diameter, concentration are important model terms. Values greater than 0.1 indicate the model terms are not practical. Hence, the velocity-diameter combination term has a more significant influence on the pressure drop than the other two combination terms.

The R square indicates that $98 \%$ of the variation in the pressure drop depends on the independent variable. In comparison, the coefficient of variation of 3.9\% explains a high degree of accuracy.

The coefficients of all the independent variables are presented in Table 7. Based on the estimated coefficient value, the weights of each independent variable on the response variable were determined. In the vertical part of the pipe, the most influential factor in the reduction of slurry pressure is the diameter of the pipe, followed by the conveying speed of the slurry, and the minor significant factor among those three independent factors is the concentration of the slurry. Although pipe diameter is negatively related to pressure drop, the effect of pipe size on pressure loss is consistent with that described in section 4.1.3. Regarding the interaction term, the $\mathrm{AB}$ has a relatively larger influence on the pressure drop compared with $\mathrm{AC}$ (velocity and concentration) and $\mathrm{BC}$ (diameter and engagement). 
Table 6. Analysis of variance for response surface model at vertical section

\begin{tabular}{llllll}
\hline Source & Sum of Squares & df Mean Square & F-value & p-value \\
\hline Model & $3.748 \mathrm{E}+07$ & 6 & $6.247 \mathrm{E}+06$ & 42.25 & $<0.0001$ \\
A-Velocity & $1.217 \mathrm{E}+07$ & 1 & $1.217 \mathrm{E}+07$ & 82.31 & $<0.0001$ \\
B-Diameter & $2.213 \mathrm{E}+07$ & 1 & $2.213 \mathrm{E}+07$ & 149.69 & $<0.0001$ \\
C-Concentration & $2.452 \mathrm{E}+06$ & 1 & $2.452 \mathrm{E}+06$ & 16.58 & 0.0022 \\
$\mathrm{AB}$ & $6.079 \mathrm{E}+05$ & 1 & $6.079 \mathrm{E}+05$ & 4.11 & 0.0701 \\
$\mathrm{AC}$ & 17755.56 & 1 & 17755.56 & 0.1201 & 0.7361 \\
BC & 99698.06 & 1 & 99698.06 & 0.6743 & 0.4307
\end{tabular}

C.V.=3.9\% R-Squared=0.98 Adj R-Squared=0.97 Predicted R-Squared=0.92

The three-dimensional response surface was plotted to reveal better the interactions of the three operating variables and how they contribute to the pressure drop during slurry conveying. Two independent variables were analyzed in each case during the investigation, while the other variable was kept constant (see Figure 20). From Figure 20a, it can be seen that the value of pressure-drop experienced a pronounced increase when the pipe diameter decreased from $0.21 \mathrm{~m}$ to $0.15 \mathrm{~m}$, and the flow velocity increased from $2 \mathrm{~m} / \mathrm{s}$ to $3 \mathrm{~m} / \mathrm{s}$ at the same time. If the diameter is constant, the pressure losses will increase rapidly with the continuous increase in slurry concentration and flow velocity. As Figure 20c illustrates, under the precondition that the flow speed remains constant, an increase in slurry concentration and a decrease in pipe diameter can together lead to a sharp rise in pressure loss.

Table 7. Coefficients of coded factors at vertical section

\begin{tabular}{|c|c|c|c|c|c|c|}
\hline \multirow{2}{*}{$\begin{array}{l}\text { Factor } \\
\text { Intercept }\end{array}$} & \multicolumn{6}{|c|}{ Coefficient Estimate df Standard Error 95\% CI Low 95\% CI High VIF } \\
\hline & 7526.21 & 1 & 93.26 & 7318.41 & 7734.01 & \\
\hline A-Velocity & 1233.42 & 1 & 135.95 & 930.50 & 1536.35 & 1.0000 \\
\hline B-Diameter & -1663.37 & 1 & 135.95 & -1966.30 & -1360.45 & 1.0000 \\
\hline \multicolumn{2}{|c|}{ C-Concentration 553.58} & 1 & 135.95 & 250.65 & 856.50 & 1.0000 \\
\hline$A B$ & -389.83 & 1 & 192.27 & -818.22 & 38.57 & 1.0000 \\
\hline$A C$ & -66.62 & 1 & 192.27 & -495.02 & 361.77 & 1.0000 \\
\hline$B C$ & -157.88 & 1 & 192.27 & -586.27 & 270.52 & 1.0000 \\
\hline
\end{tabular}




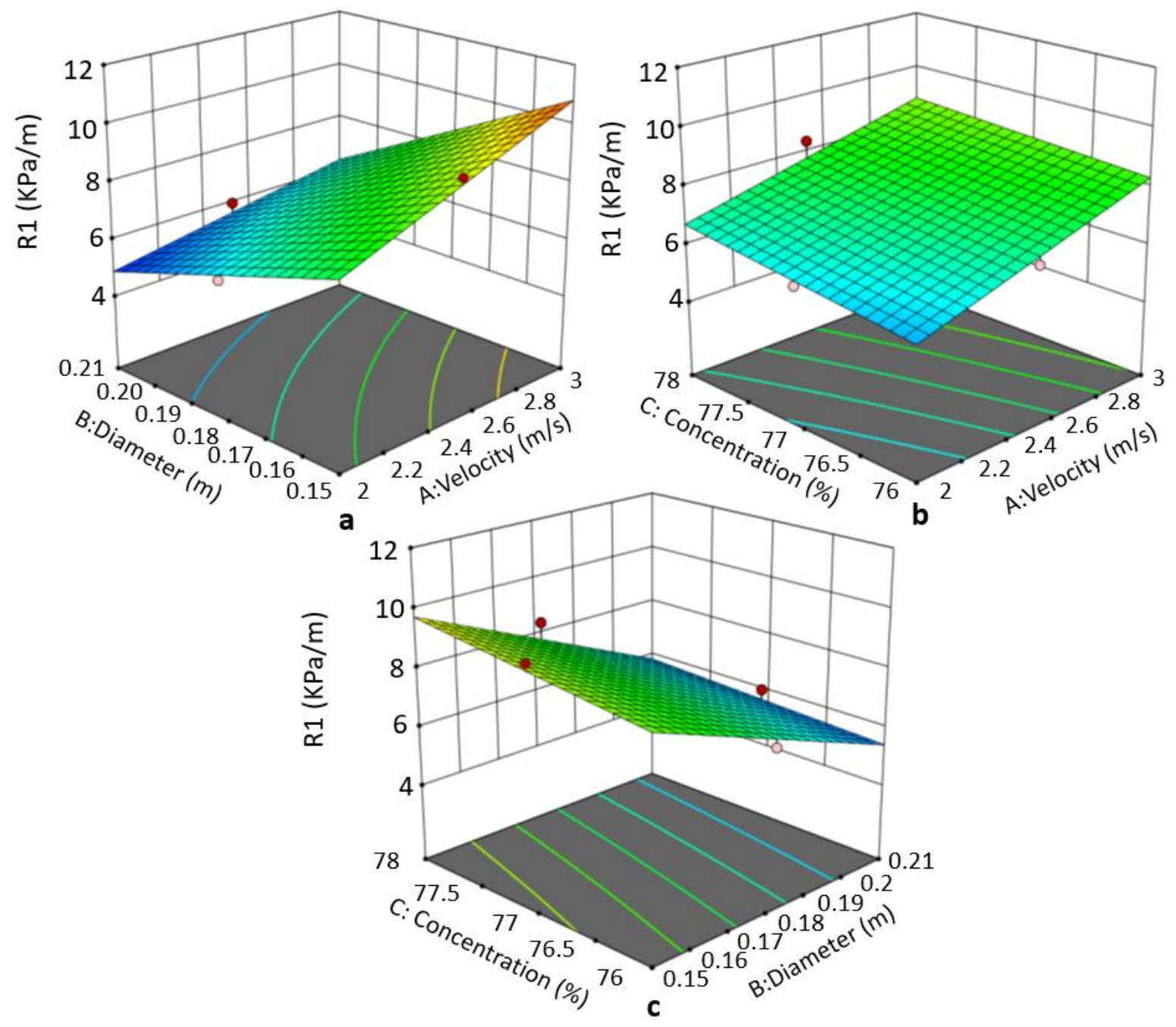

Figure 20. Response surface at vertical section

\subsubsection{Response surface analysis at bend section}

According to the P-value, the outstanding practicality of the $2 \mathrm{FI}$ model is confirmed at the pipe bends. And except all the three investigated dependent variables (namely velocity, diameter, and concentration) have a significant influence on the responding pressure drop, the interaction term $\mathrm{AB}$ has a considerable influence as well (see Table 8).

From Table 9, the weights of each independent variable and combination term on the effect of pressure drop can be derived from the estimated coefficient. Unlike in vertical pipes, velocity is the most important factor affecting the pressure in the bend section. On the other hand, slurry concentration followed the pipe diameter and ranked the third dominating 
independent variable in determining pressure drop, although pipe diameter and pressure drop are negatively correlated.

Figure 21 shows the effect of the combination of pipe diameter, slurry concentration, and flow velocity on pressure drop at the bend section. When the slurry concentration was kept constant, the combination of increased flow velocity and reduced pipe diameter led to a dramatic increase in the amount of pressure loss (see Fig. 21a). As demonstrated in Figure $21 \mathrm{~b}$, flow velocity and slurry concentration jointly controlled the pressure variation tendency; there was, however, a relatively intensive increase in pressure loss with an equivalent increment inflow velocity when the slurry concentration is low. Although the corresponding value is different, Figure 21c shows a similar response surface to Figure 20c.

Table 8. Analysis of variance for response surface model at bend section

\begin{tabular}{llllll}
\hline Source & Sum of Squares & df Mean Square & F-value & p-value \\
\hline Model & $4.075 \mathrm{E}+07$ & 6 & $6.791 \mathrm{E}+06$ & 56.19 & $<0.0001$ \\
A-Velocity & $2.052 \mathrm{E}+07$ & 1 & $2.052 \mathrm{E}+07$ & 169.76 & $<0.0001$ \\
B-Diameter & $1.627 \mathrm{E}+07$ & 1 & $1.627 \mathrm{E}+07$ & 134.65 & $<0.0001$ \\
C-Concentration & $3.091 \mathrm{E}+06$ & 1 & $3.091 \mathrm{E}+06$ & 25.57 & 0.0005 \\
AB & $6.207 \mathrm{E}+05$ & 1 & $6.207 \mathrm{E}+05$ & 5.14 & 0.0469 \\
AC & 81827.46 & 1 & 81827.46 & 0.6771 & 0.4298 \\
BC & $1.648 \mathrm{E}+05$ & 1 & $1.648 \mathrm{E}+05$ & 1.36 & 0.2700 \\
C.V.=4.96\% & R-Squared=0.96 Adj R-Squared=0.94 & Predicted R-Squared $=0.87$ \\
\hline
\end{tabular}

Table 9. Coefficients of coded factors at bend section

\begin{tabular}{lllllll}
\hline Factor & \multicolumn{6}{c}{ Coefficient Estimate df Standard Error 95\% CI Low 95\% CI High VIF } \\
\hline Intercept & 8193.75 & 1 & 84.32 & 8005.89 & 8381.62 & \\
A-Velocity & 1601.43 & 1 & 122.91 & 1327.57 & 1875.29 & 1.0000 \\
B-Diameter & -1426.22 & 1 & 122.91 & -1700.09 & -1152.36 & 1.0000 \\
C-Concentration & 621.55 & 1 & 122.91 & 347.68 & 895.41 & 1.0000 \\
AB & -393.92 & 1 & 173.82 & -781.21 & -6.62 & 1.0000 \\
AC & -143.03 & 1 & 173.82 & -530.32 & 244.27 & 1.0000 \\
BC & -202.99 & 1 & 173.82 & -590.29 & 184.30 & 1.0000 \\
\hline
\end{tabular}




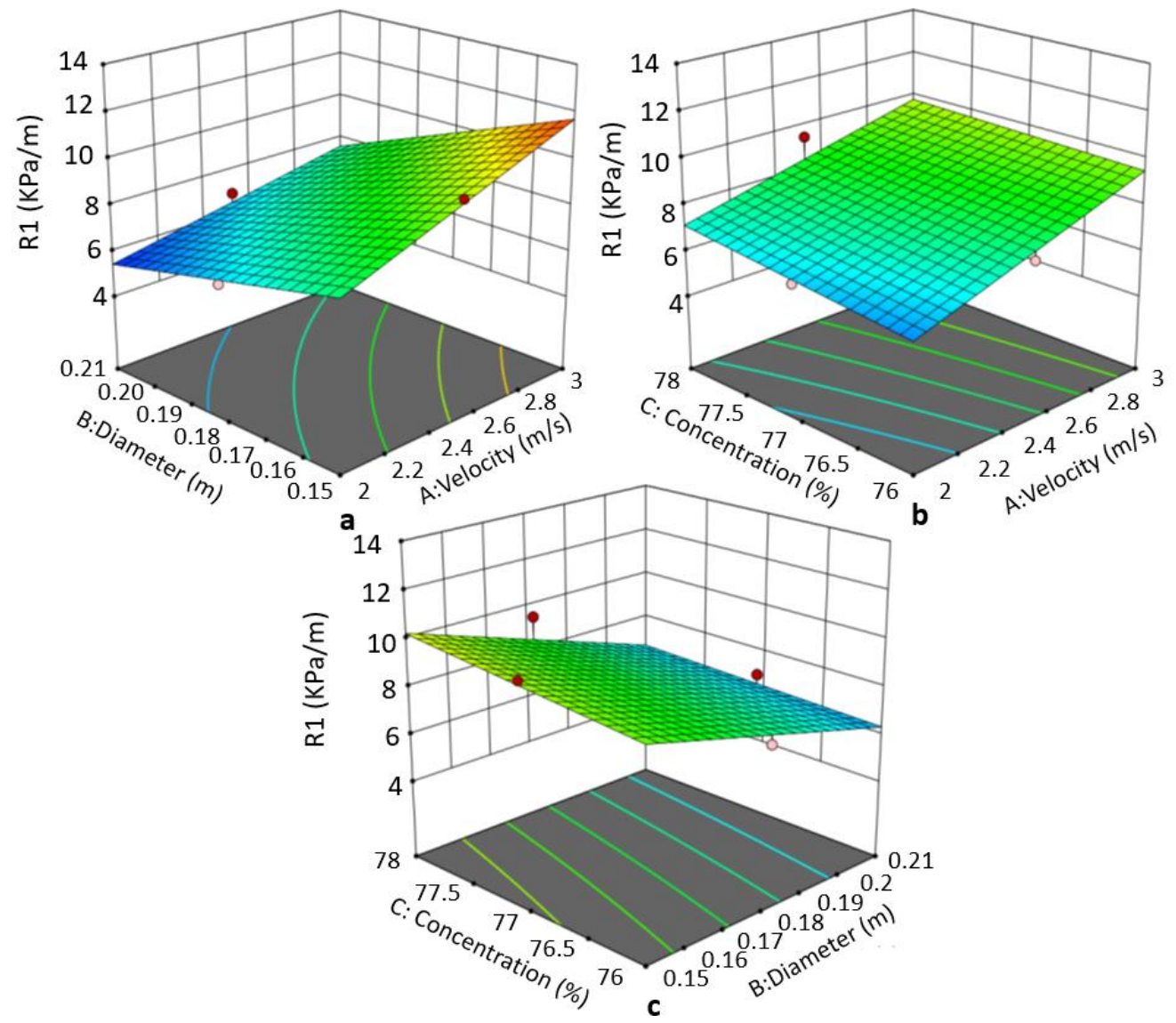

Figure 21. Response surface at bend section

\subsubsection{Response surface analysis at the horizontal section}

The R-square and adjusted R-square have proved the accuracy of the 2FI model in analysing the pressure drop dataset. The p-values in Table 10 show that flow velocity, pipe diameter, and slurry concentration can remarkably influence the pressure loss of slurry flowing through the horizontal section of the conveying pipe.

Table 10. Analysis of variance for response surface model at horizontal section

\begin{tabular}{llllll}
\hline Source & Sum of Squares & df Mean Square & F-value & p-value \\
\hline Model & $3.365 \mathrm{E}+07$ & 6 & $5.608 \mathrm{E}+06$ & 11.90 & 0.0005 \\
A-Velocity & $1.197 \mathrm{E}+07$ & 1 & $1.197 \mathrm{E}+07$ & 25.41 & 0.0005 \\
B-Diameter & $1.753 \mathrm{E}+07$ & 1 & $1.753 \mathrm{E}+07$ & 37.21 & 0.0001 \\
C-Concentration & $3.190 \mathrm{E}+06$ & 1 & $3.190 \mathrm{E}+06$ & 6.77 & 0.0264 \\
$\mathrm{AB}$ & $6.135 \mathrm{E}+05$ & 1 & $6.135 \mathrm{E}+05$ & 1.30 & 0.2804 \\
$\mathrm{AC}$ & $1.480 \mathrm{E}+05$ & 1 & $1.480 \mathrm{E}+05$ & 0.3142 & 0.5875 \\
BC & $1.895 \mathrm{E}+05$ & 1 & $1.895 \mathrm{E}+05$ & 0.4021 & 0.5402
\end{tabular}

C.V. $=6.07 \%$ R-Squared=0.95 Adj R-Squared $=0.93$ Predicted R-Squared $=0.84$ 
Table 11. Coefficients of coded factors at horizontal section

\begin{tabular}{lllllll}
\hline Factor & \multicolumn{6}{l}{ Coefficient Estimate df Standard Error 95\% Cl Low 95\% CI High VIF } \\
\hline Intercept & 7432.39 & 1 & 166.49 & 7061.43 & 7803.34 & \\
A-Velocity & 1223.36 & 1 & 242.69 & 682.61 & 1764.12 & 1.0000 \\
B-Diameter & -1480.49 & 1 & 242.69 & -2021.25 & -939.73 & 1.0000 \\
C-Concentration & 631.48 & 1 & 242.69 & 90.72 & 1172.23 & 1.0000 \\
AB & -391.63 & 1 & 343.22 & -1156.38 & 373.12 & 1.0000 \\
AC & -192.38 & 1 & 343.22 & -957.13 & 572.36 & 1.0000 \\
BC & -217.64 & 1 & 343.22 & -982.38 & 547.11 & 1.0000 \\
\hline
\end{tabular}

The value of the coefficient estimate in Table 11 tells that the independent variable with the most significant influence on pressure drop is the pipe diameter. On the other hand, the $\mathrm{AC}$ (velocity and concentration) interaction term is the least influencing independent factor.

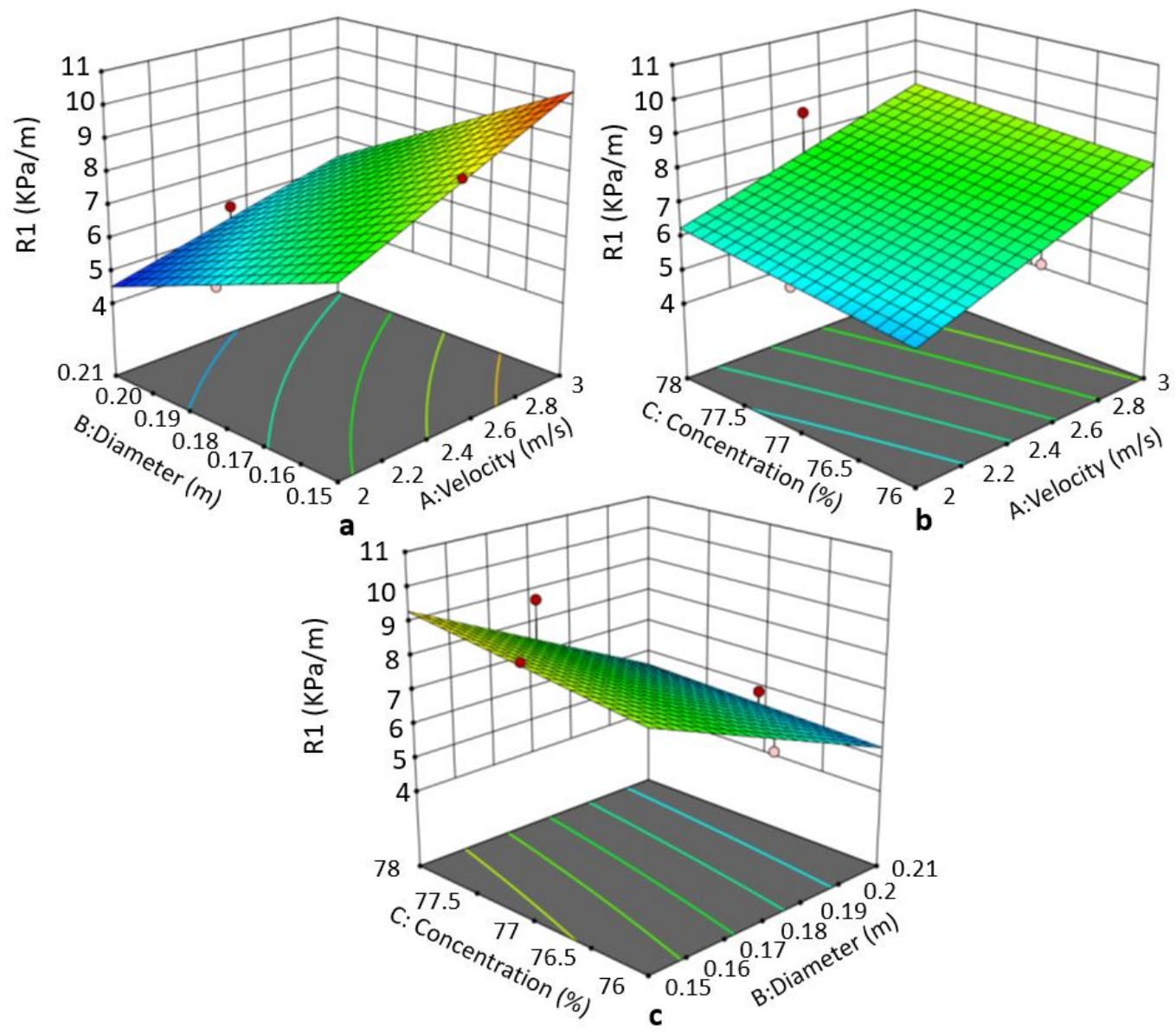

Figure 22. Response surface at the horizontal section 
Figure 22 reveals the three-dimensional response surface of pressure drop at the horizontal section of the pipe. The general changing tendency of the pressure drop under the action of all the three independent variables is similar to the corresponding one in vertical section of the pipe except for some differences in specific values.

\section{Conclusion}

When transporting slurry in a pipeline, the pressure loss is influenced by numerous factors. The three most important of which are the pipeline's diameter, the concentration of the slurry, and the flow velocity. However, different factors affect the pressure in other parts of the pipeline in the actual practice. In this paper, through a numerical simulation study and mathematical analysis, the following conclusions can be obtained:

- The rheological characteristics of the slurry flowing through the bend differ from the flow in other parts, such as vertical or horizontal sections. Therefore, it is advisable to present special treatment on the bent part for a more scientific pipe network design.

- Although many independent variables play an essential role in pressure drop, this role is not invariant, and the weight of the influence of each independent variable varies with its position in the pipeline. For instance, flow velocity is the dominant factor in the bend section in the present study. At the same time, in the vertical and horizontal areas, pipe diameter leads a role in determining the reduction value of pressure.

- Response surface methodology shows the influence of the independent variable on the dependent variable in a vivid three-dimensional diagram and screens out the major and minor factors utilizing mathematical-statistical analysis. Thus, it has been proved to be a practical tool in pipeline design in this paper. 


\section{Declaration}

\section{Funding}

The authors did not receive support from any organization for the submitted work.

Conflict of interest

The authors have no competing interests to declare that are relevant to the content of this article. 


\section{References}

1. Bharathan, B., McGuinness, M., Kuhar, S., Kermani, M., Hassani, F. P. and Sasmito, A. P. (2019). Pressure loss and friction factor in non-Newtonian mine paste backfill: Modelling, loop test and mine field data. Powder Technology, 344(15): 443-453. https://doi.org/10.1016/j.powtec.2018.12.029

2. Bharathan, B., McGuinness, M., Kuhar, S., Kermani, M., Hassani, F. P. and Sasmito, A. P. (2019). Pressure loss and friction factor in non-Newtonian mine paste backfill: Modelling, loop test and mine field data. Powder Technology, 344(15): 443-453. https://doi.org/10.1016/j.powtec.2018.12.029

3. Crawford, N M; Cunningham, G, \& Spence, S W T (2007). An experimental investigation into the pressure drop for turbulent flow in $90^{\circ}$ elbow bends. Proceedings of the Institution of Mechanical Engineers, Part E: Journal of Process Mechanical Engineering, 221(2), 77-88. doi:10.1243/0954408jpme84

4. Chhabra R.P. (2010). Non-Newtonian Fluids: An Introduction. In: Krishnan J., Deshpande A., Kumar P. (eds) Rheology of Complex Fluids. Springer, New York, NY. https://doi.org/10.1007/978-1-4419-6494-6-1

5. Chandel, S., Seshadri, V. and Singh, S. N. (2009). Effect of additive on pressure drop and rheological characteristics of fly ash slurry at high concentration. Particulate Science and Technology, 27(3): 271-284. https://doi.org/10.1080/02726350902922036

6. Chen, J., Chen, Q., Zhang, Q., and Li, H. (2015). Computer simulation of filling slurry pipeline transportation using Fluent. Science \& Technology Review, 33(9): 64-68. https://doi.org/10.3981/j.issn.1000-7857.2015.09.011

7. Chen, X., Zhou, J., Chen, Q., Shi, X. and Gou, Y. (2017). CFD simulation of pipeline transport properties of mine tailings three-phase foam slurry backfill. Minerals, 7(149): 1-19. https://doi.org/10.3390/min7080149

8. Cayeux E. and Leulseged A. (2020). The effect of thixotropy on pressure losses in a pipe. Energies, 6165 (13): 1-23. https://doi.org/10.3390/en13236165

9. Chen, S., Du, Z., Zhang, Z., Yin, D., Feng, F., Ma, J.. (2020b). Effects of red mud additions on gangue-cemented paste backfill properties. Powder Technology, $367833-$ 840. DOI: https://doi.org/10.1016/j.powtec.2020.03.055

10. Eesa, M., Barigou, M. (2009). CFD investigation of the pipe transport of coarse solids in laminar power law fluids. Chemical Engineering Science 64 (2), S. 322-333. DOI: 10.1016/j.ces.2008.10.004.

11. Gao S, Zhao G, Guo L, Zhou L, Yuan K. (2021) Utilization of coal gangue as coarse aggregates in structural concrete, Construction and Building Materials, Volume 268, 121212, https://doi.org/10.1016/j.conbuildmat.2020.121212.

12. Gao X., Li T., Rogers W.A., Smith K., Gaston K., Wiggins G., Parks J.E. II (2020). Validation and application of a multiphase CFD model for hydrodynamics, temperature field and RTD simulation in a pilot scale biomass pyrolysis vapor phase upgrading reactor. Chemical Engineering Journal. doi: https://doi.org/10.1016/j.cej.2020.124279

13. Gharib, N., Bharathan, B., Amiri, L., McGuinness, M., Hassani, F. P. and Sasmito, A.P. (2016). Flow characteristics and wear prediction of Herschel-Bulkley non-Newtonian paste backfill in pipe elbows. The Canadian Journal of Chemical Engineering, 95(6): 1181-1191. https://doi.org/10.1002/cjce.22749

14. Haixin, Z. (2018). Study on the rheological properties and pressure loss of filling slurry with unclassified tailings in pipeline. Master's thesis, North China University of Science and Technology. S. 30-36. 
15. Huang, Y., Zheng, W., Zhang, D. and Xi, Y. (2019). A modified Herschel-Bulkley model for rheological properties with temperature response characteristics of polysulfonated drilling fluid. Energy Sources, Part A: Recovery, Utilization, and $\begin{array}{lll}\text { Environmental } \quad \text { Effects, } & \text { 42(12): }\end{array}$ https://doi.org/10.1080/15567036.2019.1604861

16. Jiang G., Wu A., Wang Y., Li J. (2019). The rheological behavior of paste prepared from hemihydrate phosphogypsum and tailing. Construction and Building Materials. 229:1-9. https://doi.org/10.1016/j.conbuildmat.2019.116870

17. Kiran R., Ahmed R. and Shlehi S. (2019). Experiments and CFD modelling for two phase flow in a vertical annulus. Chemical Engineering Research and Design, 153:201211. https://doi.org/10.1016/j.cherd.2019.10.012

18. Kaczmarczyk, K., Kruk, J., Ptaszek, P. and Ptaszek, A. (2021). Pressure drop method as a useful tool for detecting rheological properties of non-Newtonian fluids during flow, Appl. Sci. 2021, 11, 6583. https://doi.org/10.3390/app11146583

19. Kazeem K.S., Akeem O. A., Mohammed D. A. (2018). Application of response surface methodology for the modelling and optimization of sand minimum transport condition in pipeline multiphase flow. Petroleum and Coal, 60 (2), 339-348

20. Liu G., Gong W., Wu H. and Lin A. (2021). Experimental and CFD analysis on the pressure ratio and entropy increment in a cover-plate pre-swirl system of gas turbine engine. Engineering Applications of Computational Fluid Mechanics, 15:1, 476-489. https://doi.org/10.1080/19942060.2021.1884600

21. Lang, L., Zhiyu, F., Chongchong, Q., Bo, Z., Lijie, G., K.I.-I.L.Song. (2019). Numerical study on the pipe flow characteristics of the cemented paste backfill slurry considering hydration effects. Powder Technology, 343, 454-464 https://doi.org/10.1016/j.powtec.2018.11.070

22. Lahiri, S. and Ghanta, K. C. (2010). Regime identification of slurry transport in pipelines: A novel modelling approach using ANN \& differential evolution. Chemical Industry and Chemical Engineering Quarterly, 16(4): 329-343. https://doi.org/10.2298/CICEQ091030034L

23. Liang C, Fall M (2016). Mechanical and thermal properties of cemented tailings materials at early ages: Influence of initial temperature, curing stress and drainage conditions. Construction \& Building Materials. 125:553-63

24. Mohsen B., Oscar E. C. H., Vicente S. F.M., Maria T. V., and Helena M. R. (2019). Computational fluid dynamics for sub-atmospheric pressure analysis in pipe drainage. Journal of Hydraulic Research, https://doi.org/10.1080/00221686.2019.1625819

25. Mohsen A., Alireza R., and Pedram T. (2020). Numerical analysis of fluid hammer in helical pipes considering non-Newtonian fluids. International Journal of Pressure Vessels and Piping 181, 104068. https://doi.org/10.1016/j.ijpvp.2020.104068

26. Mehta D., Krishnan A., Radhakrishnan T., Lier J. B. Von and Clemens F. H.L.R. (2021). Assessment of numerical methods for estimating the wall shear stress in turbulent Herschel-Bulkley slurries in circular pipes. Journal of hydraulic research, 59(2): 196213. https://doi.org/10.1080/00221686.2020.1744751

27. Picchi, D., Ullmann, A., and Brauner, N. (2018). Modeling of core-annular and plug flows of Newtonian/non-Newtonian shear-thinning fluids in pipes and capillary tubes. International Journal of Multiphase Flow 103 (1), S. 43-60. DOI: 10.1016/j.ijmultiphaseflow.2018.01.023. 
28. Picchi D., Poesio P., Ullmann A., and Brauner N. (2017). Characteristics of stratified flows of Newtonian/non-Newtonian shear-thinning fluids. International Journal of Multiphase Flow. doi: 10.1016/j.ijmultiphaseflow.2017.06.005

29. Qi C., Chen Q., Fourie A., Zhao J. and Zhang Q. (2018). Pressure drop in pipe flow of cemented paste backfill: Experimental and modeling study. Powder Technology Volume. 333,(15): 9-18. https://doi.org/10.1016/j.powtec.2018.03.070

30. Shi, Q., Xu, G., Wang, D. et al. (2021) Chain pillar optimization at a longwall coal mine based on field monitoring results and numerical model analysis. Arab J Geosci 14, 2537. https://doi.org/10.1007/s12517-021-08843-0

31. Senapati, P. K., Mishra, B. K. (2012). Design considerations for hydraulic backfilling with coal combustion products (CCPs) at high solids concentrations. Powder Technology 229, S. 119-125. DOI: 10.1016/j.powtec.2012.06.018.

32. Sercan G., and Oney E. (2020). Eric van Oort Frictional pressure losses of NonNewtonian fluids in helical pipes: Applications for automated rheology measurements. Journal of Natural Gas Science and Engineering, ( 73 ) 1-16. https://doi.org/10.1016/j.jngse.2019.103042

33. Swamy, M., Gonzalez Diez, N. and Twerda, A. (2015). Numerical modelling of the slurry flow in pipelines and prediction of flow regimes. WIT Transactions on Engineering Sciences, 89(2015): 311-322. https://doi.org/10.2495/MPF150271

34. Stat-Ease Inc. https://www.statease.com/software/design-expert/

35. Taibi, H. and Messelmi, F. (2018). Effect of yield stress on the behavior of rigid zones during the laminar flow of Herschel-Bulkley fluid. Alexandria Engineering Journal, 57(2): 1109-1115. https://doi.org/10.1016/j.aej.2017.01.001

36. Wang D, Barakos G, Cheng Z, Mischo H, Zhao J.(2022) Numerical simulation of pressure profile of mining backfill fly-ash slurry in an L-shaped pipe using a validated Herschel-Bulkley model. Journal of Sustainable Cement-Based Materials. http://dx.doi.org/10.1080/21650373.2021.2012723

37. Wu, D., Yang, B. and Liu, Y. (2015). Pressure drop in loop pipe flow of fresh cemented coal gangue-fly ash slurry: Experiment and simulation. Advanced Powder Technology, 26(3): 920-927. https://doi.org/10.1016/j.apt.2015.03.009

38. Wu, A., Yang, Y., Cheng, H-Y., Chen, S-M. and Han, Y. (2018). Status and prospects of paste technology in China. Chinese Journal of Engineering, 40(5): 518-525. https://doi.org/10.13374/j.issn2095-9389.2018.05.001

39. Xie, Y, Chi X, Li H, Wang F, Yan L, Zhang B, and Zhang Q. (2021). Coal and Gangue Recognition Method Based on Local Texture Classification Network for Robot Picking Applied Sciences 11, no. 23: 11495. https://doi.org/10.3390/app112311495

40. Yang, X., Xiao, B., Gao, Q., He, J. (2020). Determining the pressure drop of cemented Gobi sand and tailings paste backfill in a pipe flow. Construction and Building Materials 255, S. 119371. DOI: 10.1016/j.conbuildmat.2020.119371.

41. Yusri I.M., Abdul Majeed A.P.P., Mamat R., Ghazali M.F., Awad Omar I., Azmi W.H. (2018). A review on the application of response surface method and artificial neural network in engine performance and exhaust emissions characteristics in alternative fuel. Renewable and Sustainable Energy Reviews, (90), 665-686, https://doi.org/10.1016/j.rser.2018.03.095. 